\title{
Modeling the isotopic composition of Antarctic snow using backward trajectories: Simulation of snow pit records
}

M. M. Helsen, ${ }^{1}$ R. S. W. van de Wal, ${ }^{1}$ M. R. van den Broeke, ${ }^{1}$ V. Masson-Delmotte, ${ }^{2}$ H. A. J. Meijer, ${ }^{3}$ M. P. Scheele, ${ }^{4}$ and M. Werner $^{5}$

Received 26 July 2005; revised 13 February 2006; accepted 7 April 2006; published 11 August 2006.

[1] The quantitative interpretation of isotope records $\left(\delta^{18} \mathrm{O}, \delta \mathrm{D}\right.$, and $d$ excess) in ice cores can benefit from a comparison of observed meteorology with associated isotope variability. For this reason we studied four isotope records from snow pits in western Dronning Maud Land (DML), Antarctica, covering the period 1998-2001. Timing and magnitude of snowfall events on these locations were monitored using sonic height rangers. For the distinguished snowfall events we evaluated the isotopic composition of the moisture during transport by combining backward trajectory calculations with isotopic modeling, using a Rayleigh-type distillation model (MCIM). The initial isotope ratio of the moisture was determined from monthly mean isotope fields from a general circulation model (ECHAM4). The trajectory analysis showed that the southern Atlantic Ocean is the major moisture source for precipitation in DML. Modeling results along the trajectories revealed that most of the isotopic depletion occurred during the last day of the transport. Finally, a diffusion model was applied to describe the diffusion in the firn layer such that the modeled isotopes could be compared with the observed isotope records. The resulting modeled isotope profiles were mostly in good agreement with the observed seasonal variability in the snow.

However, at low temperatures (especially on the Antarctic interior), magnitude of the total distillation was underestimated. Regarding the $d$ excess parameter, our results show a large influence of advection height on the final value of $d$ excess in precipitation. This in turn points to the importance of the vertical structure of $d$ excess over the oceanic source region, which obscures the classical interpretation of this parameter in terms of temperature and relative humidity in the moisture source region.

Citation: Helsen, M. M., R. S. W. van de Wal, M. R. van den Broeke, V. Masson-Delmotte, H. A. J. Meijer, M. P. Scheele, and M. Werner (2006), Modeling the isotopic composition of Antarctic snow using backward trajectories: Simulation of snow pit records, J. Geophys. Res., 111, D15109, doi:10.1029/2005JD006524.

\section{Introduction}

[2] Ice cores from polar regions contain a wealth of paleoclimatic information [e.g., GRIP Members, 1993; Petit et al., 1999; North Greenland Ice Core Project Members, 2004; EPICA Community Members, 2004]. The most important parameter from these ice cores used as a proxy for temperature $(T)$ changes is the isotopic composition of water $\left(\delta^{18} \mathrm{O}\right.$ and/or $\delta \mathrm{D}$, usually expressed in per mill as the deviation from the Vienna Standard Mean Ocean Water, VSMOW). The strong empirical relationship between mean

\footnotetext{
${ }^{1}$ Institute for Marine and Atmospheric Research Utrecht, Utrecht University, Utrecht, Netherlands.

${ }^{2}$ Laboratoire des Sciences du Climat et de l'Environnement, UMR CEA/CNRS 1572, L'Orme des Merisiers CEA, Saclay, Gif sur Yvette, France.

${ }^{3}$ Centre for Isotope Research, Groningen, Netherlands.

${ }^{4}$ Royal Netherlands Meteorological Institute, De Bilt, Netherlands.

${ }^{5}$ Max-Planck-Institute for Biogeochemistry, Jena, Germany.

Copyright 2006 by the American Geophysical Union. 0148-0227/06/2005JD006524\$09.00
}

annual $T$ and the isotopic composition $\delta$ of snow is the basis of the use of stable water isotopes as a climate proxy. Furthermore, the second-order parameter deuterium excess $\left(d=\delta \mathrm{D}-8^{*} \delta^{18} \mathrm{O}\right.$, hereafter called $d$ excess $)$ contains additional information about nonequilibrium fractionation of moisture, as was first synthesized by Dansgaard [1964]. As such, $d$ excess is often used to infer climatic information from both the source region of the moisture and of the precipitation site [e.g., Stenni et al., 2001; Cuffey and Vimeux, 2001; Masson-Delmotte et al., 2003].

[3] Although water isotope ratios are regarded as a powerful tool to investigate paleoclimate [e.g., Jouzel et al., 1997, 2003], some controversy exists to what extent this proxy can be used as a $T$ indicator, since the $\delta-T$ relation varies in space and time [e.g., Robin, 1983; International Atomic Energy Agency, 1992; Cuffey et al., 1995; Johnsen et al., 1995; Jouzel et al., 1997, 2003; Masson-Delmotte et al., 2003; Landais et al., 2004]. Moreover, in low accumulation areas, the shortterm correlation (i.e., over several years) between $\delta$ and local $T$ is not strong enough to translate isotope records with confidence into $T$ changes [e.g., Helsen et al., 2005]. 


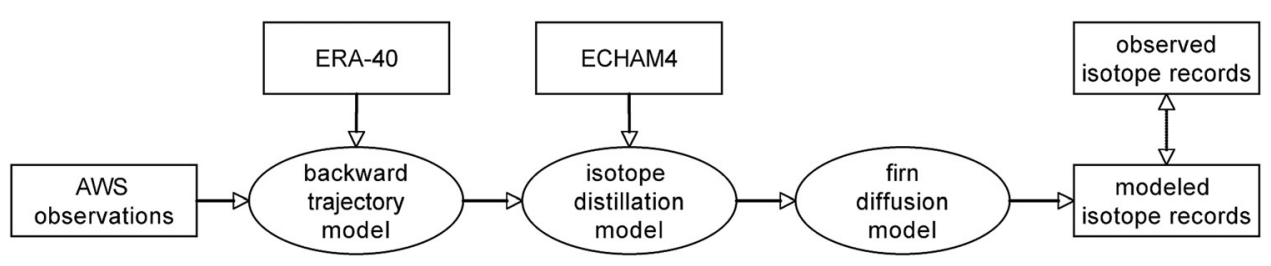

Figure 1. Schematic outline of the approach.

[4] Apart from local $T$, numerous other factors influence the isotopic composition of precipitation, such as condensation temperature [e.g., Dansgaard, 1964; Aldaz and Deutsch, 1967; Peel et al., 1988], changing conditions in the water vapor source area [Boyle, 1997; Cuffey and Vimeux, 2001], microphysical processes in clouds during snow formation [Fisher, 1991; Ciais and Jouzel, 1994], changes in magnitude of the ratio between advective and turbulent transport [Kavanaugh and Cuffey, 2003], changes in strength of the inversion layer [Van Lipzig et al., 2002], seasonality in precipitation [Werner et al., 2000].

[5] To provide the $\delta-T$ relationship a better physical basis, attempts have been made to model the isotopic fractionation of atmospheric water, either using Lagrangian parcel models based on Rayleigh distillation or using general circulation models (GCMs) equipped with water isotope tracers. The GCM approach is very suitable for the validation of the $\delta-T$ relationship since it offers the possibility to take into account all the relevant processes involved in the determination of the $\delta$ value. Moreover, with increasing resolution GCMs are increasingly capable to reproduce global and regional patterns of isotope variability [e.g., Joussaume et al., 1984; Hoffmann et al., 1998; Werner and Heimann, 2002; Noone and Simmonds, 2002b; Vuille et al., 2003]. However, the complexity of GCMs reduces their usefulness in terms of interpretation. Besides that, GCMs in climate mode generate their own internal variability of e.g., timing of accumulation, which hampers direct comparison with observed isotope records.

[6] On the other hand, Lagrangian parcel models describe isotopic fractionation of moisture in an isolated air parcel, from a single moisture source toward a precipitation site. In these models, details of cloud processes are often parameterized, which enables them to account for the bulk effect of cloud processes on kinetic isotopic fractionation [Jouzel and Merlivat, 1984; Ciais and Jouzel, 1994]. Because of their relative simplicity, these models are suitable to study the influences of different processes along transport. Moreover, the influence of nonequilibrium fractionation (both in the moisture source region and along transport) on the $d$ excess is largely based on results from this type of Lagrangian parcel models [Merlivat and Jouzel, 1979; Johnsen et al., 1989; Ciais et al., 1995; Vimeux et al., 1999]. However, these models are often poorly constrained by meteorological data. In an attempt to improve this, Helsen et al. [2004] combined back trajectory calculations with isotopic modeling using a Lagrangian parcel model, for a major snowfall event in Dronning Maud Land (DML), Antarctica. They revealed a general inconsistency in assumptions in this type of model, regarding the (noncontinuous) saturation of air masses that transport moisture to the polar regions. Furthermore, they showed that the moisture overlying the South
Atlantic Ocean was initially more depleted than expected from local evaporative conditions.

[7] In the present study we aim to increase our knowledge about the controls on polar isotopic variability, by extending the approach of Helsen et al. [2004], combining isotopic modeling with meteorological data, to be able to compare modeling results with observed isotope records. Figure 1 gives a general outline of the followed approach. We use 4 years of automatic weather station (AWS) data to infer the accumulation history of four different sites in western DML. After establishing the accumulation history (section 2), we use back trajectory calculations to trace the transport history of the moisture (section 3). Then, we combine this meteorological data with isotope distillation modeling, using a modified Rayleigh-type fractionation model, which is able to deal with the occurrence of undersaturation and evaporative recharge (section 4). This gives us modeled isotopic values of the detected snowfall events, which still cannot readily be compared with the observed isotope records from the snow pits, since postdepositional diffusion has smoothed the original values of the individual events. Therefore we simulate the diffusion process (Appendix A), and the resulting modeled isotope records are compared with observations in section 5. In section 6 a discussion follows, and conclusions are drawn in section 7 .

\section{Study Area and Accumulation History}

[8] The mass balance of western DML has been monitored for several years using AWSs [Reijmer and Van den Broeke, 2003]. For the present study, we use results from four AWSs situated along a transect connecting the coastal area (AWS 4), with the high Antarctic plateau (AWS 9) (Figure 2). The escarpment region (AWS 5 and 6) forms the transition between these two areas. The accumulation is relatively low in this area, and ranges from $74 \mathrm{~kg} \mathrm{~m}^{2} \mathrm{yr}^{-1}$ on the Antarctic plateau (AWS 9) to $393 \mathrm{~kg} \mathrm{~m}^{2} \mathrm{yr}^{-1}$ on the ice shelf (AWS 4). Table 1 gives a summary of the topographic and meteorological characteristics of these sites.

[9] The AWSs are equipped with a sonic height ranger (SHR) (Campbell SR50) that measured the local (change in) surface height. This instrument enables us to retrieve the exact timing of snowfall events [Helsen et al., 2005]. The SHR record of the surface height change is plotted in Figure 3a. The accumulation is discontinuous; sudden increases of the snow surface are followed by longer periods of slowly decreasing or constant surface height. The sudden increases of the surface are most likely the result of snowfall. However, a net deposition of drifting snow cannot be ruled out. The surface slowly subsided during periods without accumulation, as a result of settling of the snow and 


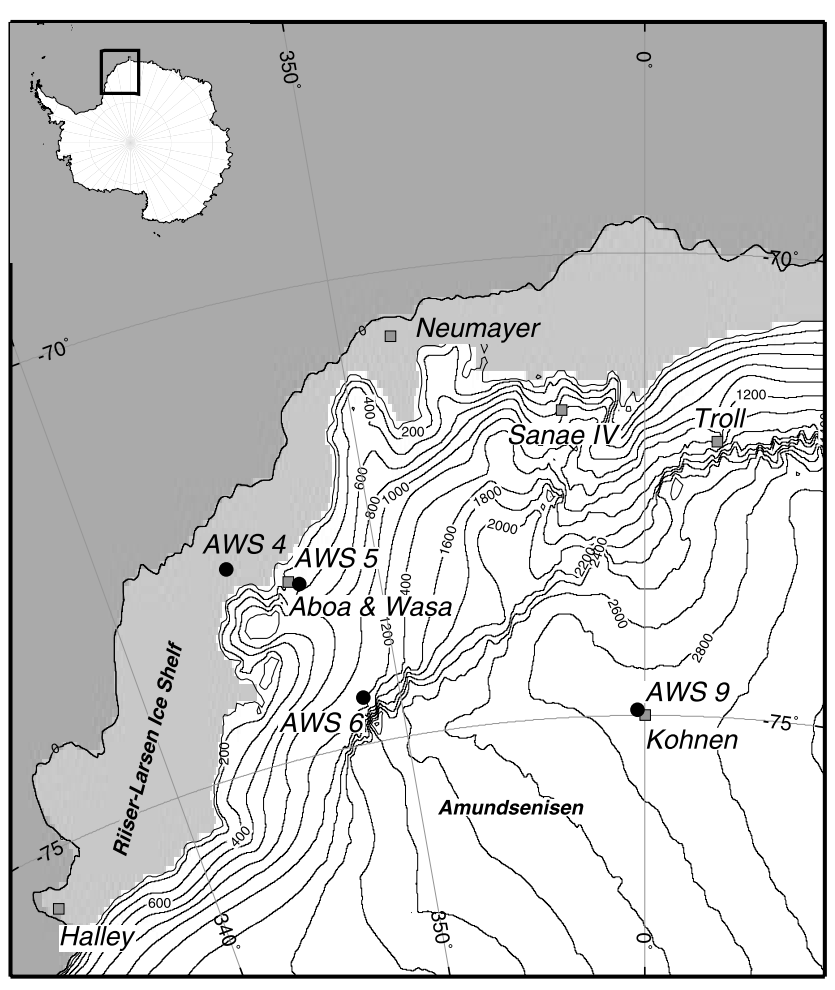

Figure 2. Map of Western Dronning Maud Land, with the locations of the automatic weather stations.

sublimation. Sudden decreases of the surface height are most likely caused by wind erosion.

[10] From these records, accumulation events that are preserved in the snow are distinguished following the procedure described in Helsen et al. [2005]. The accumulation history of each site is hereby resolved in 12-hour intervals. Because of compaction of the underlying snow, the distance between a certain snow layer and the SHR increases slowly through time. We corrected for this effect using measured density profiles, to give a best estimate of the depth of each layer at the end of the monitoring period. This was done to facilitate a comparison with measured isotope records (Table 2, see section 5). However, due to unknown changes in the density profiles through time, the final depth of each snowfall event is only an estimate, which hampers an event-based comparison of observed and modeled isotope records (see section 5).

[11] Figure $3 \mathrm{~b}$ displays an overview of the timing and magnitude of the preserved snowfall events. The intermittent character of the accumulation is apparent, resulting in only few large snowfall events that account for the bulk of the total accumulation. This has resulted in the exclusion of entire seasons from the isotope records, which can hamper the interpretation of isotopic variability on a seasonal scale. At AWS 4, 5 and 6 the accumulation is highest in autumn and winter (with $65-75 \%$ of annual accumulation). AWS 9 shows a more evenly distribution of accumulation through the year [Reijmer and Van den Broeke, 2003]. The relation between local $T$ and the isotope records is further discussed by Helsen et al. [2005]. In the present study, we follow an alternative approach, by explicitly modeling the isotopic composition of each accumulation event.

\section{Trajectories}

[12] In order to model the isotopic composition of snowfall, information is needed about the transport history of the moisture. We obtained this information by using a trajectory model, that calculates 5-day backward trajectories for air parcels arriving at the locations of the AWSs. This trajectory model was developed by the Royal Netherlands Meteorological Institute (KNMI [Scheele et al., 1996]), and it computes the large-scale three-dimensional displacement of an air parcel during a time step $\Delta t$, using an iterative scheme:

$$
X_{n+1}=X_{0}+\frac{\Delta t}{2}\left[v\left(X_{0}, t\right)+v\left(X_{n}, t+\Delta t\right)\right]
$$

where $X_{0}$ is the position vector of the air parcel at time $t, X_{n}$ is the $n$th iterative approximation of the position vector at $t+\Delta t$, and $v(X, t)$ is the three-dimensional wind vector at position $X$ and time $t$. The iteration time step $\Delta t$ is $-10 \mathrm{~min}$. The iteration stops when the horizontal distance between $X_{n}$ and $X_{n+1}$ is less than $300 \mathrm{~m}$, and the relative vertical (pressure) difference $\left(p_{n+1}-p_{n}\right) / p_{n+1}$ is less than $10^{-4}$. For comparison, the mean horizontal displacement in $10 \mathrm{~min}$ is typically $4-5 \mathrm{~km}$.

[13] As an input for the trajectory model we used the European Centre for Medium-range Weather Forecasts (ECMWF) reanalysis (ERA-40) data set. We used the

Table 1. AWS Topographic and Climate Characteristics, 1998-2001 ${ }^{\mathrm{a}}$

\begin{tabular}{|c|c|c|c|c|}
\hline & AWS 4 & AWS 5 & AWS 6 & AWS 9 \\
\hline Start of observation & 22 Dec 1997 & 3 Feb 1998 & 15 Jan 1998 & 1 Jan 1998 \\
\hline End of observation & 21 Dec 2001 & 2 Feb 2001 & 14 Jan 2002 & 31 Dec 2001 \\
\hline Location & $72^{\circ} 45.2^{\prime} \mathrm{S}, 15^{\circ} 29.9^{\prime} \mathrm{W}$ & $73^{\circ} 06.3^{\prime} \mathrm{S}, 13^{\circ} 09.9^{\prime} \mathrm{W}$ & $74^{\circ} 28.9^{\prime} \mathrm{S}, 11^{\circ} 31.0^{\prime} \mathrm{W}$ & $75^{\circ} 00.2^{\prime} \mathrm{S}, 0^{\circ} 00.4^{\prime} \mathrm{E}$ \\
\hline Elevation, $m$ above sea level & 34 & 363 & 1160 & 2892 \\
\hline Surface slope, $\mathrm{m} \mathrm{km}^{-1}$ & 0.1 & 13.5 & 15.0 & 1.3 \\
\hline $\mathrm{SSMB}^{\mathrm{b}} \mathrm{kg} \mathrm{m}^{-2} \mathrm{yr}^{-1}$ & 393 & 179 & 267 & 74 \\
\hline Snow density, $\mathrm{kg} \mathrm{m}^{-3}$ & 406 & 383 & 396 & 307 \\
\hline Temperature, $\mathrm{K}$ & 253.4 & 256.8 & 252.6 & 230.0 \\
\hline Relative humidity, \% & 93 & 83 & 78 & 93 \\
\hline Specific humidity, $\mathrm{g} \mathrm{kg}^{-1}$ & 1.03 & 1.01 & 0.72 & 0.17 \\
\hline $10 \mathrm{~m}$ wind speed, $\mathrm{m} \mathrm{s}^{-1}$ & 5.7 & 7.9 & 7.7 & 4.8 \\
\hline
\end{tabular}

${ }^{\mathrm{a}}$ From Van den Broeke et al. [2004].

${ }^{\mathrm{b}} \mathrm{SSMB}$, specific surface mass balance. 

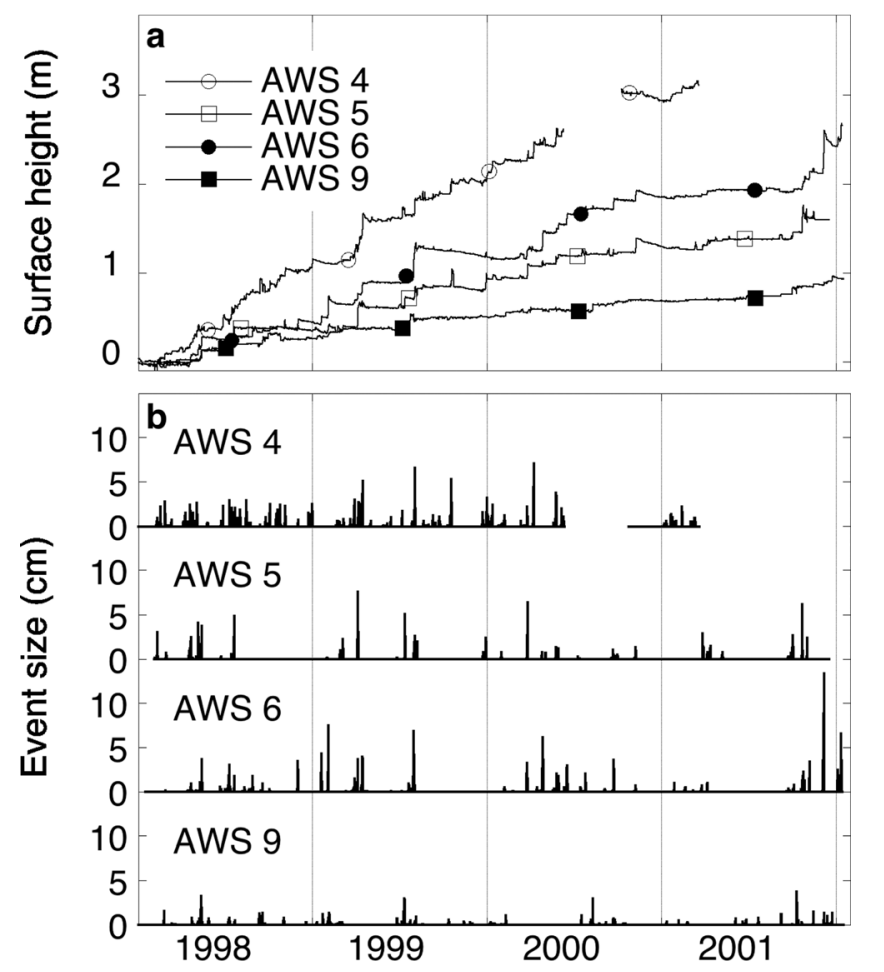

Figure 3. (a) Surface height and (b) identified accumulation events from the AWSs over the period 1998-2001. Because of a malfunctioning SHR, the accumulation history of AWS 4 could only be established until early 2001, with a data gap in winter 2000 .

analyzed fields, to obtain the most accurate estimate of the "true" state of the atmosphere. The spectral resolution of this archive is T159 (corresponding to $\sim 125 \mathrm{~km}$ horizontal spatial resolution and 60 vertical levels), but as input for the trajectory model these data are gridded on a constant $1.0^{\circ}$ resolution in the horizontal plane, 60 vertical levels, and 6-hourly data. Interpolation in space and time was therefore necessary. The spatial interpolation of the trajectory model is bilinear in the horizontal, and linear with $\log (p)$ in the vertical. The interpolation in time is quadratic, but for temperature and moisture this produced unrealistic variations, which made us apply a linear interpolation for these parameters.

[14] Uncertainties in the resulting trajectories can be considerable. The choice of trajectory type, interpolation schemes and spatial resolution of the wind fields introduces an uncertainty in the order of $1000 \mathrm{~km}$ after 5-day backward calculation [Stohl et al., 1995]. In reality, the error can be even larger, due to the presence of convective systems (e.g., fronts, convective storms) or the vicinity of the earth surface, which can cause the parcel to lose its identity. These errors are difficult to quantify and not included in the uncertainty estimate, so computed trajectories must be interpreted with care.

[15] Apart from the above mentioned difficulties, an additional problem that can influence the isotope modeling is that a trajectory model only traces the advective pathway of an air parcel. This is not necessarily equal to the pathway of the moisture itself, since turbulent moisture fluxes are neglected. Nevertheless, we apply the trajectory method because we consider it the best available estimate of transport histories for individual snowfall events.

[16] For the Antarctic region this trajectory model has previously been used to define moisture source regions for several deep drilling sites [Reijmer et al., 2002], whereas Helsen et al. [2004] used the trajectory model in combination with an isotope model to investigate the isotopic distillation of Antarctic moisture along transport.

[17] To capture the best estimate of the transport history of the moisture that brings snowfall to the study sites, the trajectories for air parcels should ideally be calculated from arrival locations at the exact time and location of the snow formation above the accumulation sites. For the timing of the snowfall events, we used the accumulation records from the SHRs (Figure 3). These records consist of accumulation amounts in 12-hour intervals, which are bounded by 0600 and $1800 \mathrm{UT}$; if accumulation occurred in such an interval, we defined the moment of snow fall either at 0000 or 1200 UT. To determine the vertical (pressure) level of snow formation, vertical profiles of cloud water content $(C W C)$ from ERA-40 were considered. We defined the height of snow formation as the level with maximum $C W C$. If successive 12-hour intervals showed accumulation, we defined the interval with the highest maximum $C W C$ as the interval with most snow fall, and in addition, this moment is regarded to be the representative timing of snow formation of this event. Then, 5-day backward trajectories were calculated from five pressure levels $(-50,-25,0,25$ and $50 \mathrm{hPa}$ ) centered around this pressure level with maximum $C W C$.

[18] Figure 4 shows the weighted mean of the trajectories calculated for all snowfall events at the AWSs. The magnitude of each accumulation event detected by the SHR (Figure $3 \mathrm{~b}$ ) is used as a weighting factor $\left(w_{i}\right)$. Using $w_{i}$, means are calculated by averaging the positions of the trajectories per time step over a sphere, resulting in a weighted mean pathway of the moisture. The main picture for all four AWSs shows a cyclonic transport path over the southern Atlantic Ocean, which is in agreement with earlier studies of moisture transport to DML [Noone et al., 1999; Reijmer et al., 2002]. To indicate the variability of the air parcel positions, covariance ellipses are plotted around the mean locations

Table 2. Characteristics of Samples Taken From Snow Pits in the Field Season 2001-2002

\begin{tabular}{lcccc}
\hline & AWS 4 & AWS 5 & AWS 6 & AWS 9 \\
\hline Location & $15 \mathrm{~m}$ from AWS 4 & $2 \mathrm{~m}$ from AWS 5 & under SHR & under SHR \\
Sampling date & 25 Dec 2001 & 17 Dec 2001 & 14 Jan 2002 & 17 Jan 2002 \\
Depth of the pit, cm & 450 & 200 & 300 & 91.5 \\
$\delta$ sampling interval, cm & 2.0 & 2.0 & 2.0 & 1.5 \\
$\rho$ sampling interval, cm & 5.0 & 5.0 & 5.0 & 2.5 \\
\hline
\end{tabular}



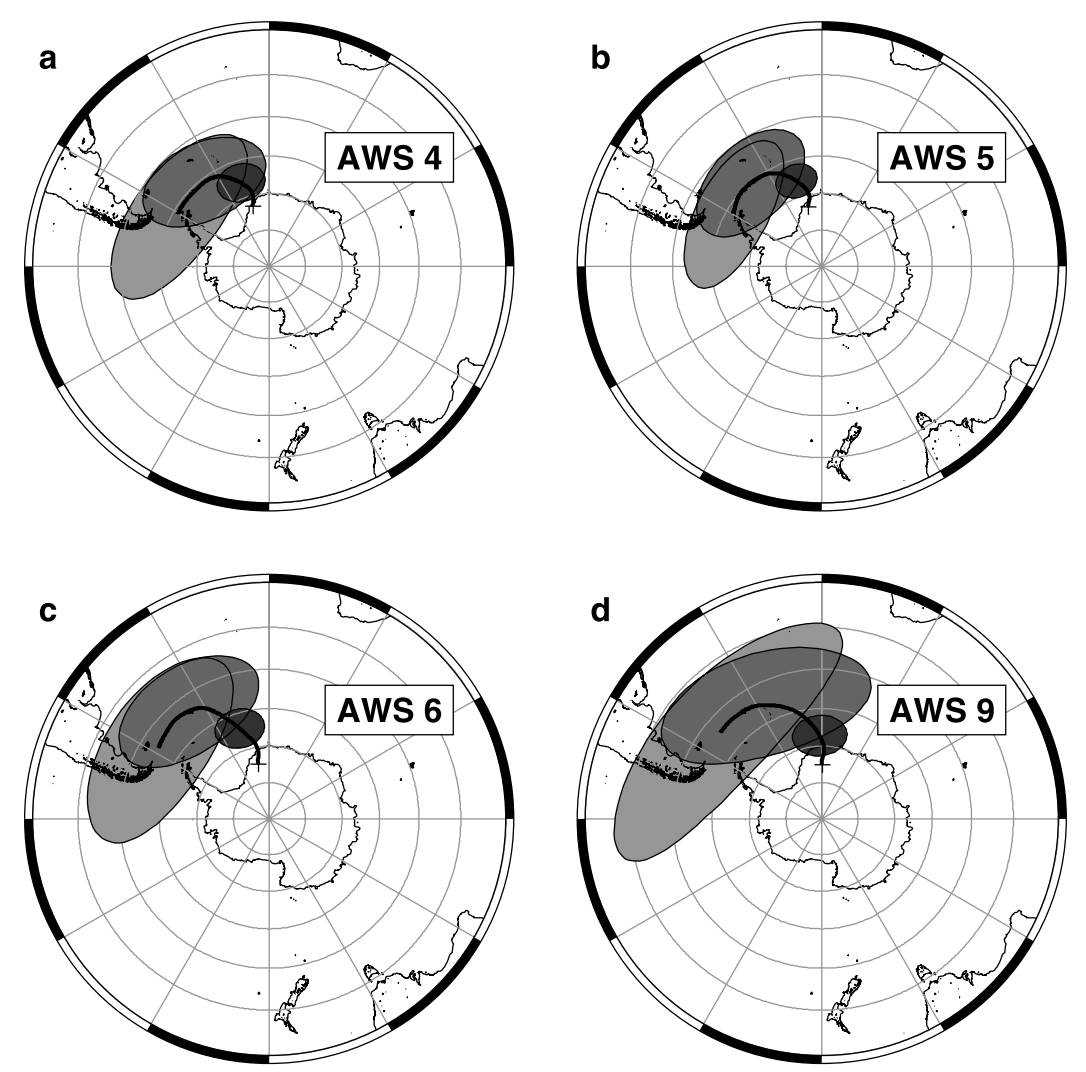

Figure 4. Weighted mean 5-day backward trajectories (thick lines) and covariance ellipses for days when snowfall occurred at (a) AWS 4, (b) AWS 5, (c) AWS 6, and (d) AWS 9. Covariance ellipses are associated with air parcel locations at 5 days (light gray), 3 days (medium gray), and 1 day (dark gray) before arrival at the study sites. Weighting is performed using the magnitude of snowfall events from Figure 3.

at 1,3, and 5 days before arrival (Figure 4). The size, shape, and angle of these ellipses are based on the weighted variances $\left(\sigma_{x}^{2}\right.$ and $\left.\sigma_{y}^{2}\right)$ and covariances $\left(\sigma_{x y}\right)$ of the position vector components ( $x$ and $y$ refer to distances on a sphere in $\mathrm{km}$ in longitudinal and latitudinal direction, respectively), in analogy with Kottmeier and Fay [1998],

$$
\begin{gathered}
\sigma_{x}^{2}=\frac{\sum_{1}^{n} w_{i}\left(x_{i}-\bar{x}\right)^{2}}{\sum_{1}^{n} w_{i}} \\
\sigma_{y}^{2}=\frac{\sum_{1}^{n} w_{i}\left(y_{i}-\bar{y}\right)^{2}}{\sum_{1}^{n} w_{i}} \\
\sigma_{x y}=\frac{\sum_{1}^{n} w_{i}\left(x_{i}-\bar{x}\right)\left(y_{i}-\bar{y}\right)}{\sum_{1}^{n} w_{i}}
\end{gathered}
$$

using $\sigma_{x}$ and $\sigma_{y}$ as lengths for the major and minor axis of the ellipse, respectively. The orientation of major axis of the ellipse is determined by $\sigma_{x y} / \sigma_{x}^{2}$.

[19] As expected, the trajectories converge from a large variability at 5 days before arrival toward a confined area 1 day before they reach their final destination. Although the pathways for the four study sites look quite similar, there is a major difference in the air parcels' position at 5 days before arrival. While the trajectories for the site on the ice shelf (AWS 4, Figure 4a) are located at $\sim 61^{\circ} \mathrm{S}$, at 5 days before arrival, the trajectories for the Antarctic plateau (AWS 9, Figure 4d) show a position at $\sim 54^{\circ} \mathrm{S}$ at 5 days before arrival.

[20] Generally, the air parcel positions are more northward for destinations higher on the Antarctic plateau. This pattern reflects an increase in advection speed. One should keep in mind that the trajectories shown here are weighted with accumulation at the arrival location. The larger advection speed of the trajectories for the plateau compared to the coastal sites can be attributed to the scarcity of cyclonic activity (and associated snowfall) in the Antarctic interior. Only intense cyclones penetrate onto the Antarctic plateau and bring snowfall to this area. Hence a large snowfall event will be associated with strong advection, which explains the more distant origin. This is in agreement with findings of Noone and Simmonds [2002a], who showed that an air parcel requires a critical amount of kinetic energy to reach the high Antarctic plateau. The difference in transport paths can have implications for the source area of the moisture, and its isotopic composition, especially regarding the $d$ excess parameter (discussed in section 6).

[21] The difference in intensity of advection is further explained by Figure 5a, which shows the pressure level of the air parcel during transport toward the arrival sites. The 

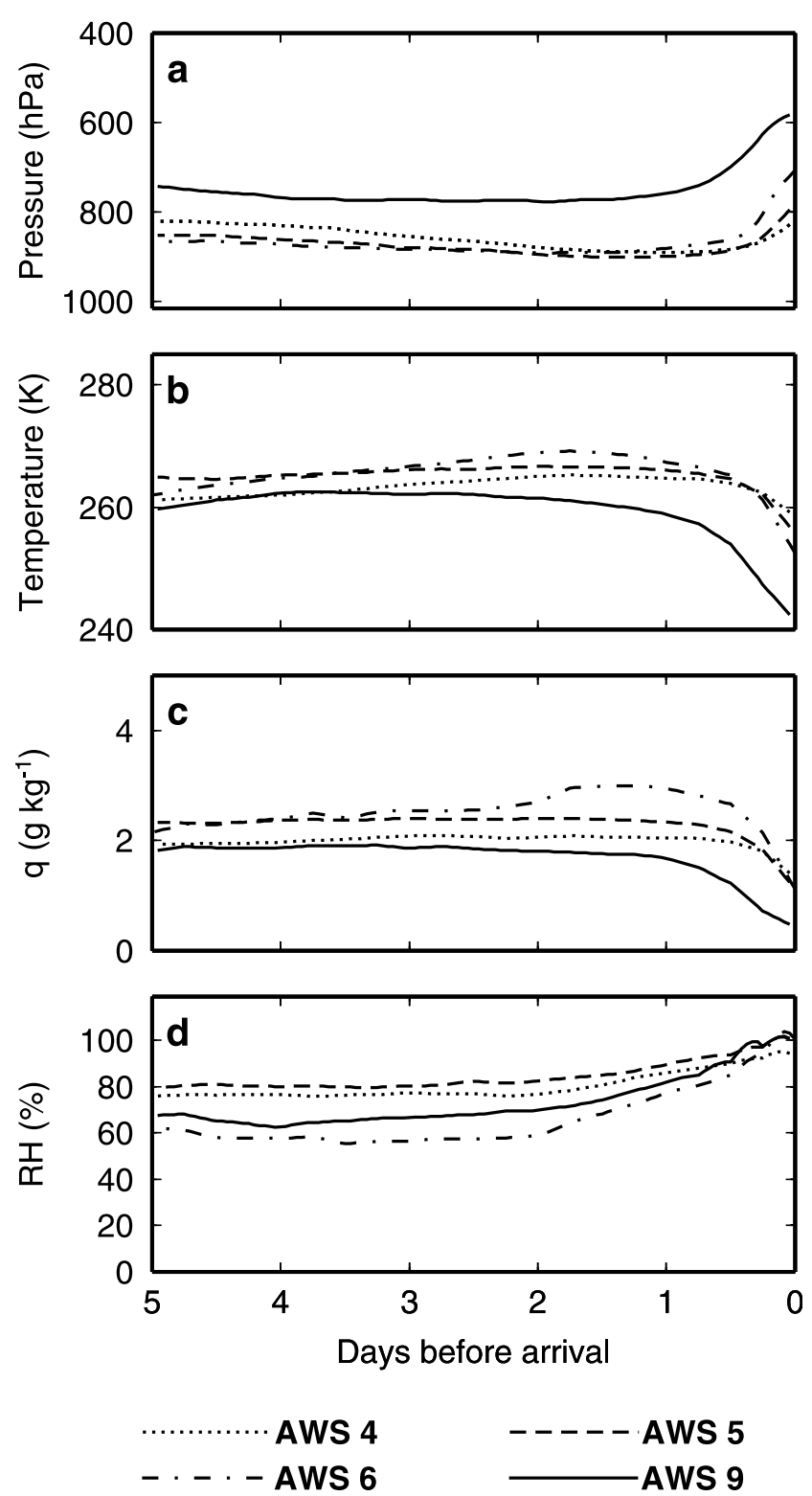

Figure 5. Weighed mean values of (a) air pressure, (b) temperature, and (c) specific and (d) relative humidity along trajectories for the four study sites.

higher altitude of AWS 9 results in a higher starting level, and this higher transport level is maintained during all 5 days before arrival. The longer advection path of the trajectories arriving at AWS 9 is obviously also associated with the higher transport path.

[22] The temperature evolution along the trajectories is shown in Figure 5b. During the major part of the transport path, $T$ remains constant, or increases slightly. Only during the final stage of the transport (last day before arrival), $T$ decreases strongly. This is the case for all sites, but most pronounced for AWS 9.

[23] The changes in specific humidity ( $q$, Figure 5c) during transport toward the arrival site are very similar to the $T$ pattern. Important to note here is that Figure 5 shows average values; individual trajectories often show large variation in height, $T$ and $q$. Increases of $q$ in the individual trajectories (not shown) occur either between 5 and 1 day before arrival, (implying moisture uptake), or the moisture has already entered the air parcel more than 5 days before arrival. The strong decrease of $T$ in the final stage of transport causes a similar drop in $q$. This decrease of $T$ and $q$ during the approach toward the Antarctic continent is of primary importance for the final isotopic composition of the moisture (see section 4).

[24] Using the variation of $q$ along the trajectories, we can find the region of maximum moisture uptake for the four study locations, by weighting the location of moisture uptake with the amount of increase of $q$, multiplied by the weighting factor for each trajectory (as in the procedure for the calculation of the weighed mean trajectories). This gives us mean values and covariance ellipses of the moisture uptake locations, which can be interpreted as the moisture source regions for the four study sites (Figure 6). The dominant moisture source regions are located over the South Atlantic Ocean, which is in line with earlier findings of, e.g., Reijmer et al. [2002]. It should be kept in mind that these source areas are determined using only moisture increases during the last 5 days of transport. The percentages in the ellipses in Figure 6 indicate the portion of the total moisture that has entered the air parcel during these last 5 days of transport. The remaining part of the moisture was already present in the air parcel at 5 days before arrival, which hampers an estimation of the source area of this moisture.

[25] The difference in trajectory length that was noticed in Figure 4 has a consequence for the moisture source regions, which is clearly visible in Figure 6. Snow that is transported inland onto the Antarctic plateau has a more distant moisture source than coastal precipitation: the moisture source for AWS 4 is located between $\sim 45^{\circ} \mathrm{S}$ and $70^{\circ} \mathrm{S}$, while the moisture source for AWS 9 is between $\sim 40^{\circ} \mathrm{S}$ and $65^{\circ} \mathrm{S}$. This is in agreement with theoretical considerations [Robin and Johnsen, 1983] and different GCM studies [Werner et al., 2001; Delaygue et al., 2000] that also point toward an increasing contribution of low-latitude moisture toward the Antarctic interior.

[26] Figure 5d presents values of relative humidity $(\mathrm{RH})$. The value of $\mathrm{RH}$ is indicative for the presence of saturated conditions, which are crucial for the occurrence of condensation and associated isotopic fractionation. We note fairly high values of RH for the trajectories of AWS 4 and 5, while the trajectories for AWS 6 and 9 show a lower value over the first part of transport, slowly increasing toward saturated values. This indicates that air parcels bringing snowfall to the coastal area of DML tend to experience more frequent saturation during the last 5 days of transport than those that travel to the more elevated interior. The latter air parcels only show saturated conditions during the final phase of transport $(\sim 1$ day). These differences in RH can have consequences for the isotopic distillation process, since we do not expect condensation (nor isotopic fractionation) during undersaturated conditions. This matter will be addressed in more detail in section 4 .

\section{Isotopic Distillation}

[27] To simulate the isotopic fractionation process of moisture in air parcels, we use the Mixed Cloud Isotopic 

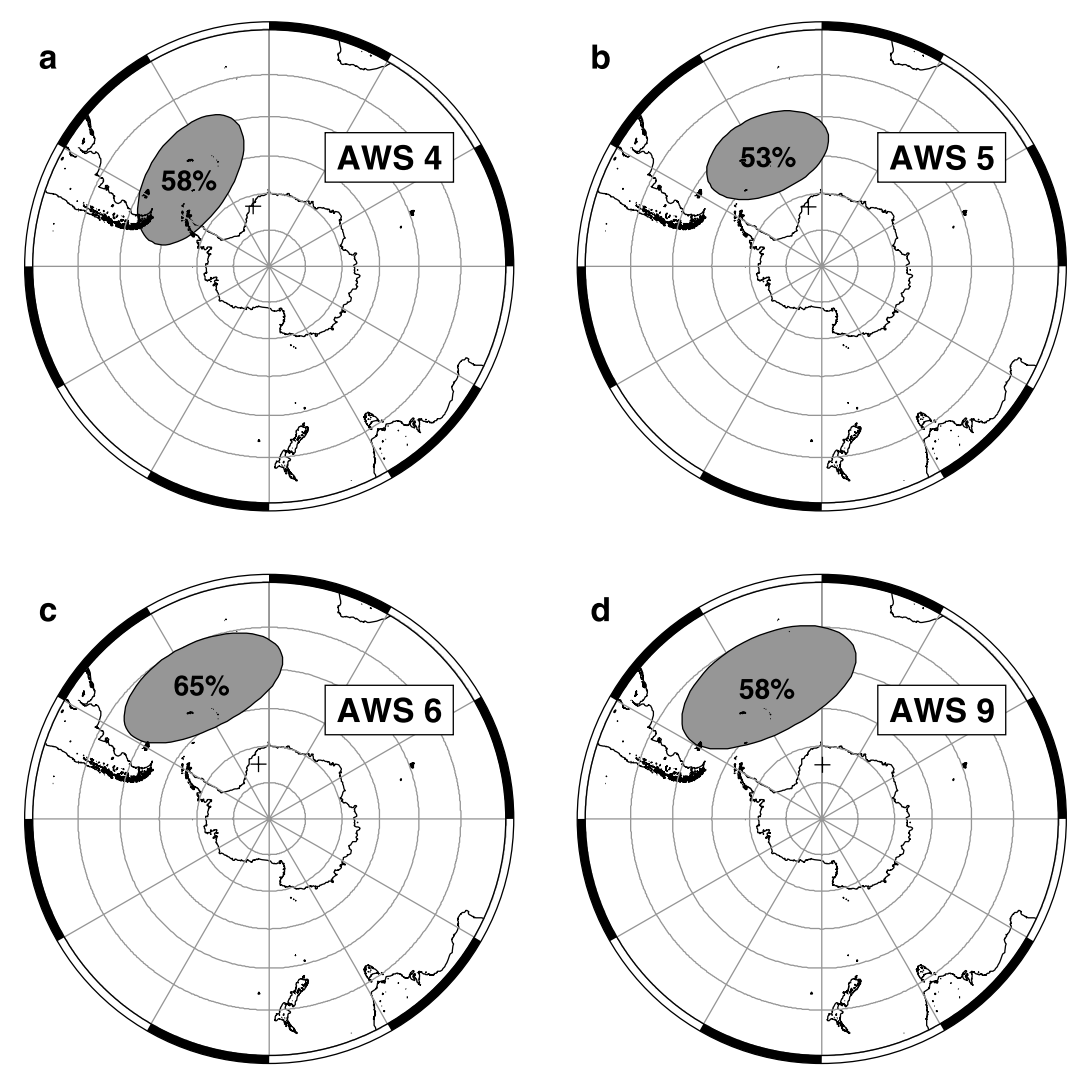

Figure 6. Covariance ellipses representing the location of moisture uptake along trajectories for (a) AWS 4, (b) AWS 5, (c) AWS 6, and (d) AWS 9. The percentages in the ellipses show the portion of the total moisture that has entered the trajectory during the last 5 days of transport.

Model (MCIM [Ciais and Jouzel, 1994]), which describes isotopic changes in an isolated Lagrangian air parcel. In principle, this model is derived from a Rayleigh distillation model as described by Dansgaard [1964]. However, improvements on the Rayleigh distillation theory (regarding the kinetic fractionation effect) have been incorporated both in the source area [Merlivat and Jouzel, 1979] and in the description of snow formation at low temperatures [Jouzel and Merlivat, 1984]. Furthermore, Ciais and Jouzel [1994] introduced a description of the processes occurring in mixed clouds, allowing the interaction of vapor, liquid and ice. These improvements have resulted in the MCIM, which has succeeded in reproducing the main characteristics of stable isotope variability in the middle and high latitudes [e.g., Jouzel et al., 1997]. In addition, the MCIM has been used to support the interpretation of the seasonal cycle at Law Dome, Antarctica [Delmotte et al., 2000; Masson-Delmotte et al., 2003].

[28] Difficulties arise when a simple isotope distillation model like the MCIM is combined with a realistic meteorological transport history of an air parcel [Helsen et al., 2004]. One of those problems concerns the definition of the isotopic composition of the initial vapor, certainly when dealing with air parcels at varying height. Furthermore, air parcels do not experience continuous saturation during transport, which is an assumption in simple isotope models. Therefore the isotope model has been modified, which is addressed hereafter.

\subsection{Initial Conditions}

[29] The initial isotopic composition of vapor $\left(\delta_{v 0}\right)$ in a Lagrangian air parcel is not easily estimated because the vapor and the ocean surface are not in isotopic equilibrium. More specifically, the value of $\delta_{v 0}$ differs from the isotopic content of evaporating water $\left(\delta_{e}\right)$ [Craig and Gordon, 1965]. However, many Rayleigh-type distillation models assume $\delta_{v 0}$ and $\delta_{e}$ to have the same value, using global-scale balance considerations between evaporation and precipitation. This enables the calculation of $\delta_{v 0}$ from conditions at the ocean surface [Merlivat and Jouzel, 1979] and this approach is known as the global-scale closure equation. However, Jouzel and Koster [1996] pointed out that, although evaporation and precipitation are in balance on a global scale, this might not be justified at the regional scale. Therefore they recommend to use GCM-generated values for the isotopic composition of the vapor $\left(\delta_{v}\right)$, from grid boxes of the surface layer overlying the ocean (as by, e.g., Delmotte et al. [2000]).

[30] Moving toward a trajectory approach, the value of $\delta_{v 0}$ cannot directly be taken from these GCM surface layer fields, since air masses are typically located $1-3 \mathrm{~km}$ above the ocean surface when the calculations start (Figure 5a). This is well above the marine atmospheric boundary layer, and the moisture in these air masses is expected to be more depleted compared to the moisture in the surface layer, due to earlier condensation cycles. Helsen et al. [2004] showed that moisture approaching the Antarctic continent has in- 

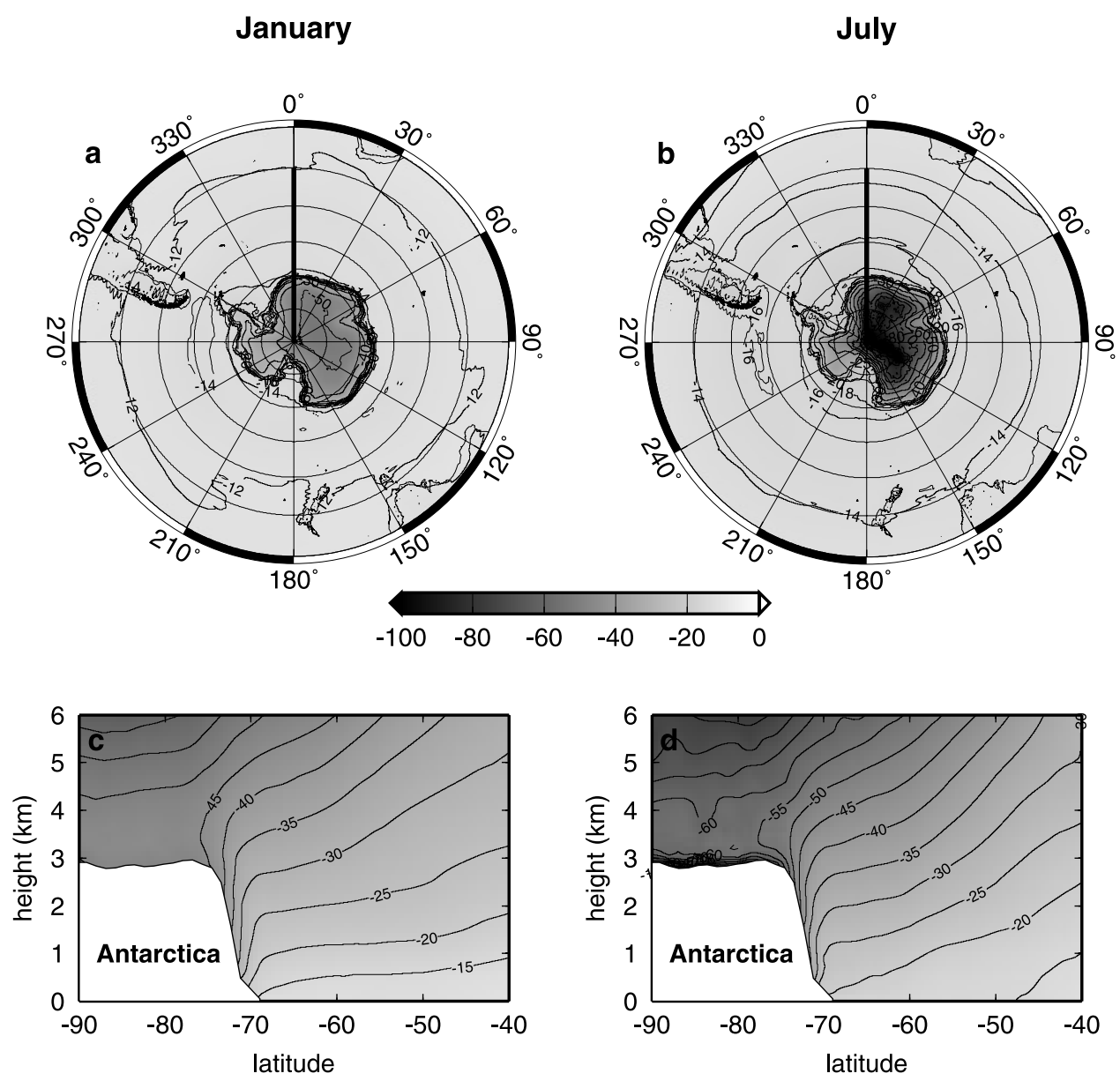

Figure 7. Mean monthly $\delta^{18} \mathrm{O}_{v}$ values of water vapor in (left) January and (right) July from ECHAM4. (a) and (b) The $\delta^{18} \mathrm{O}_{v}$ distribution of the level closest to the surface and (c) and (d) vertical cross sections along the $0^{\circ} \mathrm{E} / \mathrm{W}$ meridian. The grey area in the lower left corner represents the Antarctic continent.

deed a more depleted $\delta_{v}$ value than can be expected from evaporation from the local ocean surface.

[31] Therefore we make use of three dimensional GCMgenerated isotope fields, from which the value of $\delta_{v 0}$ is taken as a starting point for the isotope model. A 20-year present-day climate run is performed with the Hamburg atmospheric climate model ECHAM4 [Roeckner et al., 1996], which includes tracers for the isotopic species $\delta^{18} \mathrm{O}$ and $\delta D$ [Hoffmann et al., 1998; Werner and Heimann, 2002]. The spectral resolution is T106 $\left(1.1^{\circ}\right.$ latitude $\times$ $1.1^{\circ}$ longitude) with 19 vertical levels. This run provides monthly mean values of the isotopic composition of water vapor for $\delta^{18} \mathrm{O}$ and $\delta D$. These fields can be regarded as an isotope climatology. With the present resolution, ECHAM4 has proven to yield a realistic spatial distribution of isotope variability [Vuille et al., 2003].

[32] To sketch the character of the isotopic distribution in these fields, Figures $7 \mathrm{a}$ and $7 \mathrm{~b}$ show values of $\delta^{18} \mathrm{O}_{v}$ of the near-surface level in January and July, respectively. Over the ocean, $\delta^{18} \mathrm{O}_{v}$ values remain relatively constant, whereas strongly depleted values are visible over the Antarctic continent. Very low values $(<-80 \%)$ are found over central Antarctica during winter, but whether these low values also occur in reality remains uncertain, since this would require strong, continuous condensation near the surface.
[33] Figures 7c and 7d show vertical slices from the ECHAM4 isotope fields, along the $0^{\circ} \mathrm{E} / \mathrm{W}$ meridian. The large vertical gradient in $\delta^{18} \mathrm{O}_{v}$ is apparent, and indicates that the vertical position of the starting point of the trajectory will be of great influence for the initial isotopic value of the moisture. Furthermore, the moisture just above the ocean surface is more depleted in July than in January, which is probably due to a stronger near-surface temperature gradient or caused by an increased sea ice extent in winter, that prohibits isotopic equilibration of the moisture with the ocean water.

[34] From the cross section in July it becomes clear that the anomalously low values over the Antarctic continent only show up in a shallow layer covering the surface. For our purpose, the ECHAM4 isotope fields are only used to define the initial value of $\delta_{v 0}$ (mostly over the ocean), and therefore these possibly spurious parts of the model data do not affect our isotopic modeling results.

[35] Figure 8 shows $d$ excess values of vapor in the ECHAM4 climatology. For the winter situation (Figures $8 \mathrm{~b}$ and 8d) very high values are found over the Antarctic continent. These high vapor $d$ excess values also produce anomalous high $d$ excess values in central Antarctic precipitation, which are not in agreement with observed $d$ excess patterns. This points to problems in the parameterization of 

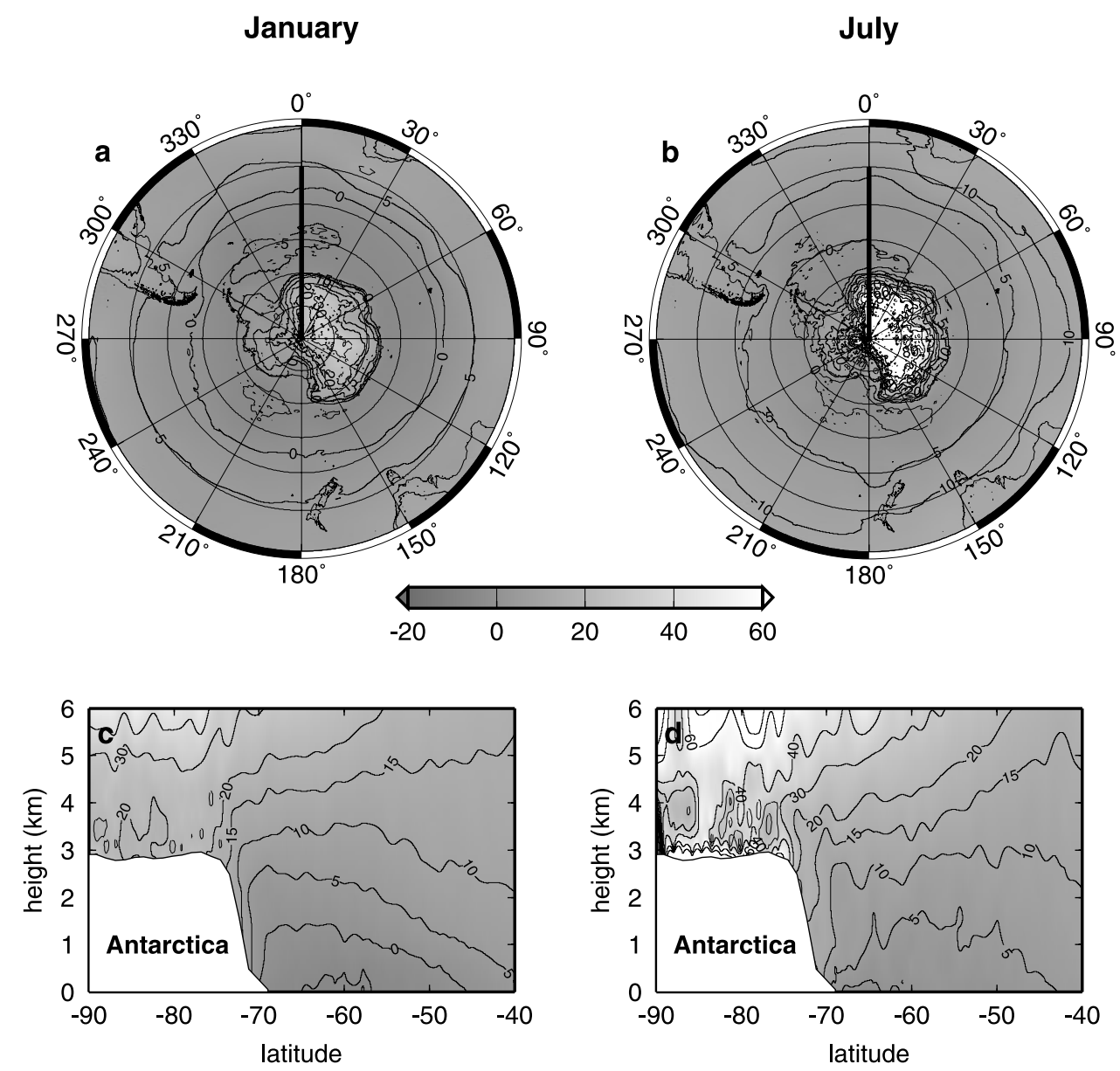

Figure 8. Same as Figure 7, but for mean monthly $d$ excess values of water vapor in (left) January and (right) July from ECHAM4. (a) and (b) The $d$ excess distribution of the level closest to the surface and (c) and (d) vertical cross sections along the $0^{\circ} \mathrm{E} / \mathrm{W}$ meridian. The grey area in the lower left corner represents the Antarctic continent.

kinetic fractionation effects occurring during snow formation in ECHAM4 [Werner et al., 2001]. Nevertheless, as explained above, these data are not expected to affect our results, since it is the isotopic composition at lower latitudes that determines the initial isotopic value of the moisture in the air parcels (Figure 4).

[36] However, the $d$ excess variability over the ocean is important for our purpose, since it determines the initial $d$ excess signature of the moisture in the air parcels. Over the ocean surface, ECHAM4 produces a gradient in $d$ excess values of the vapor, with increasing values with altitude. Since the initial altitude of the trajectories (5 days before arrival) can vary considerably, the vertical gradient of $d$ excess obviously is of large influence on our modeling results. This matter will be addressed in more detail in section 6 .

[37] It should be noted that the use of climatological mean ECHAM4 isotope values as initial isotopic values can introduce a significant error in our final modeling results. Isotopic values in single storm events can show large deviations from the mean state (in the order of $5-10 \%$ [Hoffmann et al., 1998]). Especially in regions where cyclonic disturbances occur only occasionally, the isotopic composition during intense storms might deviate substan- tially from the mean state. However, while there exist no reanalyses of atmospheric isotope fields, climatological values seem to be the best available estimate for defining the initial isotopic composition.

\subsection{Isotopic Recharge}

[38] Apart from the above mentioned difficulties in determining the initial isotopic composition, realistic transport histories often show subsequent increases in $q$ before the final rain-out toward the precipitation site. The trajectories show that such increases in $q$ occur over the southern Atlantic Ocean (Figure 6). These increases in $q$ are associated with isotopic recharge, i.e., the uptake of moisture with a different isotopic composition. Since the MCIM addresses the isotopic changes in an isolated air parcel, any increase of $q$ that exceeds the total amount of moisture in the air parcel will result in model failure. To enable realistic description of the isotopic evolution of air parcels, the MCIM has been adapted to account for such increases of $q$, assuming that this moisture is mixed into the air parcel from ambient air.

[39] Similarly as for the initial isotopic composition of the vapor $\left(\delta_{v 0}\right)$, we use the ECHAM4 isotope fields to determine the isotopic composition of the ambient water vapor $\left(\delta_{v, \text { ECHAM }}\right)$. As soon as all available cloud water and/or ice is reevaporated, the additional increase of $q$ is "extracted" 

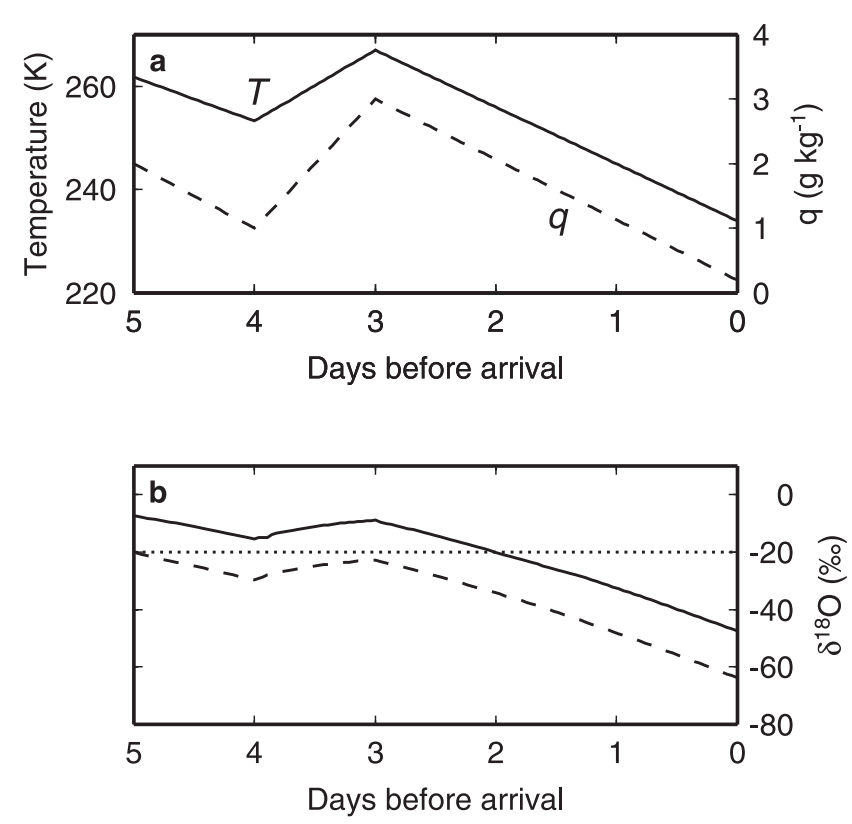

Figure 9. Output from the adapted MCIM showing the effect of isotopic recharge with a constant isotopic composition of the ambient moisture. (a) Imposed $T$ (solid line) and $q$ (dashed line) history as a function of time and (b) isotopic composition of the ambient moisture (dotted line) and the resulting isotopic changes in vapor (dashed line) and precipitation (solid line).

from ambient air, and the resulting $\delta_{v}(t)$ value is calculated by mixing $\delta_{v, \operatorname{ECHAM}}(t)$ with $\delta_{v}(t-\Delta t)$. Using this approach, a strong increase of $q$ will result in a value of $\delta_{v}$ close to the value of $\delta_{v, \text { ECHAM }}$ at that particular location, which is schematically illustrated in Figure 9.

[40] Figure 9 is a schematic history of $T$ and $q$, in which an isotopic recharge occurs between 3 and 4 days before arrival. In this case we kept the isotopic composition of the ambient moisture constant $\left(\delta^{18} \mathrm{O}_{v \text {,ECHAM }}=-20 \%\right.$, dotted line in Figure 9b). Between 4 and 5 days before arrival, fractionation occurs in the same way as in the original MCIM. Then, between 3 and 4 days before arrival, $T$ (solid line in Figure 9a) and $q$ (dashed line in Figure 9a) in the air parcel increase, and the isotopic composition of the vapor $\left(\delta^{18} \mathrm{O}_{v}\right.$, dashed line in Figure $\left.9 \mathrm{~b}\right)$ increases as well. The value of $\delta^{18} \mathrm{O}_{v}$ approaches $\delta^{18} \mathrm{O}_{v, \text { ECHAM }}$ but will never entirely reach its value due to the presence of the depleted vapor at 4 days before arrival. After this recharge, a drop in $T$ causes a fractionation comparable to the original model. The resulting final precipitation is slightly more depleted compared to the case without an earlier condensation cycle.

\subsection{Fractionation Threshold}

[41] As demonstrated in section 3 (in particular for AWS 6 and 9), on average, the trajectories only show saturated conditions during the final stage of transport, and lower values of RH during earlier stages of the transport. It is not expected that moisture in an undersaturated air mass experiences isotopic fractionation. However, simple Rayleightype isotope models like the MCIM calculate the isotopic distillation as a function of only $T$ and $p$, assuming constant saturation from the source regions to the deposition site.
This is not in line with realistic moisture transport, as was earlier noted by Helsen et al. [2004].

[42] In the ECMWF model (and many other GCMs), cloud water is assumed to form when RH exceeds a specified threshold [Tiedtke, 1993; Jakob, 1999]. In analogy with these models, we included a parameter $\mathrm{RH}_{\text {threshold }}=$ $80 \%$ as an indicative value for the presence of clouds. The $\mathrm{RH}$ value obtained from the trajectories can be considered representative for grid average conditions but not necessarily on cloud microscale level. This in an important difference, since the MCIM calculates kinetic fractionation effects as a function of the amount of supersaturation (i.e., $\mathrm{RH}>100 \%$ ). To overcome this discrepancy, we follow the original MCIM in defining its a supersaturation value as a function of $T$ (using the parameterization of Petit et al., 1991), to ensure realistic modeling results for $d$ excess, while we follow our trajectory data as an indicator for the presence of clouds.

[43] The implication of the introduction of $\mathrm{RH}_{\text {threshold }}$ is schematically explained in Figure 10. We impose a schematic $T, p$ and $q$ history on an air parcel (Figure 10a). Initially, the air parcel is well below saturation $(\mathrm{RH}=60 \%)$. As $T$ decreases and $q$ is kept constant, $\mathrm{RH}$ increases. As soon as $\mathrm{RH}>\mathrm{RH}_{\text {threshold, }}$, condensation is assumed to occur, and, although the RH value according to the imposed humidity history are still below $100 \%$, on a cloud microscale level (super-) saturated conditions are defined as a function of $T$ and $p$ following the original tuning of the MCIM described by Ciais and Jouzel [1994]. Isotopic
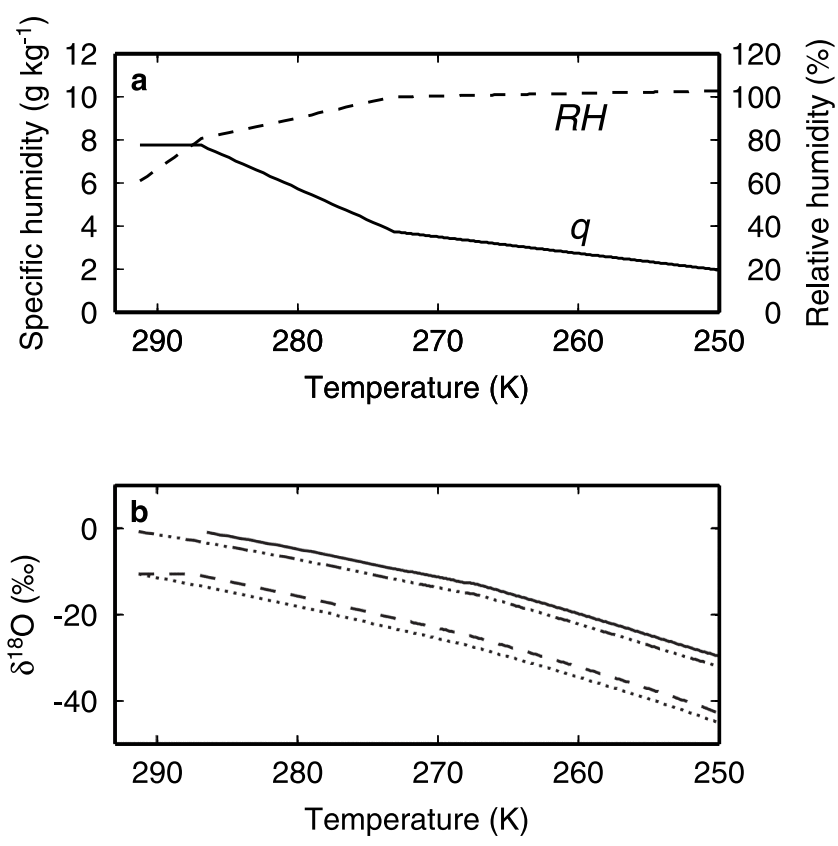

Figure 10. Output from of the adapted MCIM showing the effect of a threshold value of $\mathrm{RH}$ for isotopic fractionation. (a) Schematic moisture changes along trajectory: specific (solid line) and relative (dashed line) humidity as a function of $T$ and (b) isotopic changes of the moisture as a function of $T$. The dashed line represents vapor in the adapted model, the solid line the resulting precipitation. The dotted line is the vapor if the original MCIM is used, and the dash-dotted line is the accompanying precipitation. 


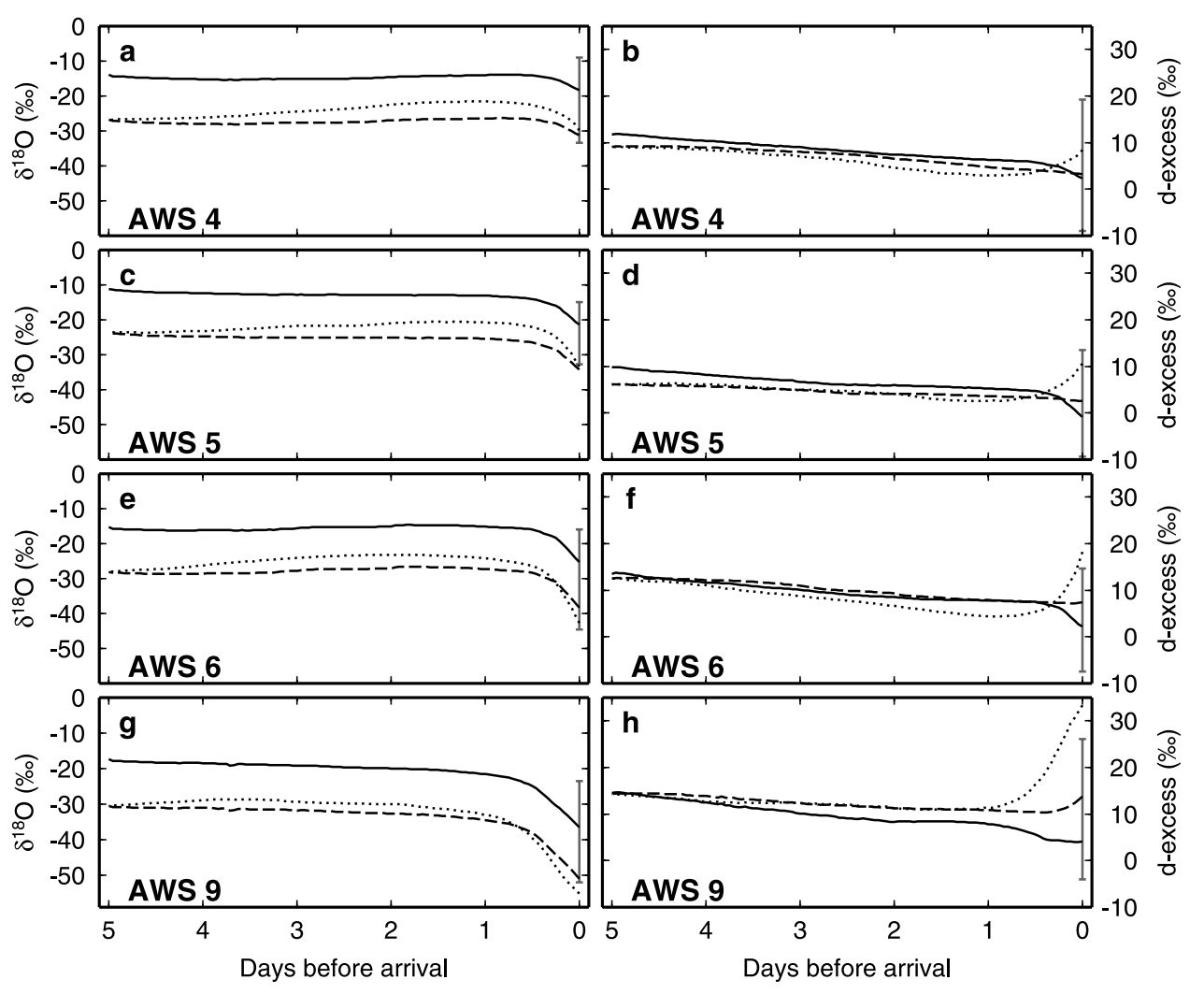

precipitation

------ vapour

vapour in ECHAM

Figure 11. Mean isotopic distillation histories along trajectories for (a, b) AWS 4, (c, d) AWS 5, (e, f) AWS 6 , and $(\mathrm{g}, \mathrm{h})$ AWS 9 . Weighted mean fractionation history (left) for $\delta^{18} \mathrm{O}$ and (right) for the $d$ excess. Minimum and maximum values of the final isotopic value of the snow are plotted at the end of each distillation history, to indicate the variability.

fractionation starts (Figure 10b), and from then on the same gradient is followed as would occur using the original MCIM. Clearly, the impact of this threshold is that the new modeled isotopic fractionation entirely depends on the difference between $T_{\mathrm{RH}=80 \%}$ and $T_{\text {final }}$. In the original MCIM, the air parcel was lifted until saturation was reached, and then followed until the final point of the trajectory. Hence the difference between the source area (at the level of saturation) and the arrival location was the main controlling parameter. The quantitative impact of $\mathrm{RH}_{\text {threshold }}$ on the final results is different for each trajectory, depending on the mutual behavior of $T$ and RH. However, this matter will be addressed in section 6 .

\subsection{Fractionation History}

[44] Weighted mean isotope distillation histories are shown in Figure 11 for the trajectories calculated for the four study sites. As for the trajectory results presented in Figure 5, weighting for the averaging are obtained from accumulation amounts (Figure 3).

[45] The mean isotopic change along transport of both $\delta^{18} \mathrm{O}$ (Figure 11, left) and $d$ excess (Figure 11, right) are shown for both vapor (dashed lines) and precipitation (solid lines). Also shown are the accompanying values of the monthly mean isotope values of the vapor from the ECHAM4 fields, at the location of the air parcels (dotted lines). Minimum and maximum values of the final precipitation are also indicated with the gray bars.

[46] The general picture from the fractionation histories in Figure 11 is that the modeled $\delta^{18} \mathrm{O}$ value of the moisture is relatively constant during most of the transport, whereas during the last day of transport the major part of the fractionation takes place. This is very well explained by the changes in $T$ and $q$ (Figure 5) during the last day of transport. The isotopic amplitude is only minor at AWS 5, since most precipitation occurred in spring or autumn [Helsen et al., 2005], while AWS 9 shows the largest amplitude.

[47] It is interesting to compare modeled $\delta^{18} \mathrm{O}_{v}$ and ambient $\delta^{18} \mathrm{O}_{v \text {,ECHAM }}$ from the ECHAM4 fields. Because of the definition of the initial state, the values of $\delta^{18} \mathrm{O}_{v \text {,ECHAM }}$ and $\delta^{18} \mathrm{O}_{v}$ are equal when the simulation starts. From that moment onward, $\delta^{18} \mathrm{O}_{v, \text { ECHAM }}$ slowly increases, while $\delta^{18} \mathrm{O}_{v}$ hardly changes, due to (on average) a stable pattern of $T, p$ and $q$. However, during the last day of transport, $\delta^{18} \mathrm{O}_{v \text {,ECHAM }}$ plunges to more negative values than $\delta^{18} \mathrm{O}_{v}$ for AWS 6 and 9 .

[48] This can be understood, since the values of $\delta^{18} \mathrm{O}_{v \text {, ЕCHAM }}$ are climatic mean values of a certain latitude and altitude. On the other hand, the values of $\delta^{18} \mathrm{O}_{v}$ are only calculated for snowfall events. In Antarctica, snowfall is generally associated with advection of much 


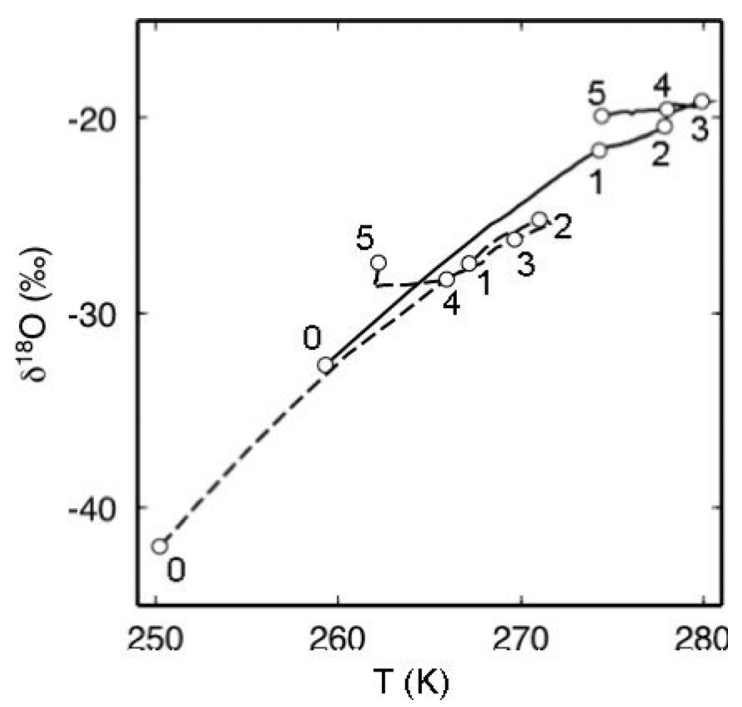

Figure 12. Seasonal mean $\delta^{18} \mathrm{O}_{v}$ distillation paths for AWS 6 as a function of $T$. Solid line represents summer (DJF) distillation, and dashed line represents winter (JJA). Numbers indicate day before arrival.

warmer air than average [e.g., Noone et al., 1999; Helsen et al., 2005]. A comparison of $T$ values from both our trajectories and in the ECHAM4 fields (not shown) indeed points to a difference in $T$. Therefore the lower gradient of $\delta^{18} \mathrm{O}_{v}$ compared to $\delta^{18} \mathrm{O}_{v, \text { ECHAM }}$ is associated with a smaller drop in $T$ during accumulation, compared to the mean temperature distribution over the Antarctic region, and hence explains why $\delta^{18} \mathrm{O}_{v}$ is higher then $\delta^{18} \mathrm{O}_{v, \text { ECHAM }}$.

[49] Focussing on the seasonal amplitude, Figure 12 shows the seasonally averaged distillation of $\delta^{18} \mathrm{O}_{v}$ as a function of $T$ for trajectories to AWS 6. The drop in $T$ (which is strongest during the last day of transport) produces a strong distillation of the moisture. The average $\delta / T$ gradient increases from $0.6 \% \mathrm{~K}^{-1}$ around the freezing point to $1.0 \% \mathrm{~K}^{-1}$ at $253 \mathrm{~K}$, which is in agreement with previous results obtained with the MCIM [Ciais and Jouzel, 1994]. Between 5 and 3 days before arrival, increases in $T$ are accompanied by isotopic recharge, which causes a somewhat irregular pattern of the average values of $T$ and $\delta^{18} \mathrm{O}_{v}$.

[50] Interestingly, looking at the difference in $T$ over which condensation occurs $(\Delta T)$ over the seasonally averaged trajectories, Figure 12 shows that $\Delta T_{\mathrm{JJA}}$ is hardly larger than $\Delta T_{\mathrm{DJF}}$. Since $\Delta T$ determines the magnitude of the isotopic distillation, not much difference would be expected in the final isotopic composition, notwithstanding that there is a seasonal difference in the $\delta^{18} \mathrm{O}$ value of the initial moisture in the air parcel. This implies that the seasonal amplitude of $\delta^{18} \mathrm{O}$ can only to a small extent be explained by seasonal changes in $\Delta T$. To a much larger extent it is a reflection of a more regional signal in $\delta^{18} \mathrm{O}$ of atmospheric moisture.

[51] We summarized the relative contribution of $\Delta T$ to the total isotopic distillation in Table 3 . The isotopic composition of the moisture that enters the air parcel appears to make a large difference for AWS 4 and 6 , whereas $\Delta T$ can explain the bulk of the seasonal isotopic cycle for AWS 5 and 9. The large isotopic differences in this initial moisture along trajectories to AWS 4 and 6 are not due to large shifts in source areas, but can partly be attributed to seasonal changes in the isotopic composition of vapor around Antarctica and also to differences in initial height of the air parcels (which can be of large influence as explained in sections 4.1 and 4.2).

[52] The changes in $d$ excess along the trajectories are shown in Figure 11 (right). In the first phase of transport, when the air parcels are located over the ocean, a gradual decrease can be observed in the $d$ excess values of both the moisture in our modeled air parcels as in the ECHAM4 fields. In the last part of the transport, when $T$ strongly drops when the parcel approaches the Antarctic continent, our modeled $d$ excess values of the vapor do not react strongly, whereas the ECHAM4 fields show strongly increasing $d$ excess values. The modeled $d$ excess values in the precipitation along the trajectories show a decrease during the $T$ drop in the final stage of transport.

[53] This drop of $d$ excess in precipitation during the final stage of transport of the air parcels appears to be in conflict with the general pattern of increasing $d$ excess values with decreasing $T$ over Antarctica, which is present in both observations [Petit et al., 1991; Dahe et al., 1994] and in model results [Hoffmann et al., 1998]. If we focus on the general behavior of $d$ excess in precipitation as a function of $T$ in our model (Figure 13, which shows results of a model run using a linear decreasing $T$ ), it appears that $d$ excess slowly decreases down to $T \sim 250 \mathrm{~K}$, and subsequently increases at lower $T$. Furthermore, changes in $p$ also play a role in the exact shape of the $d$ excess curve. On average, our trajectories did not encounter low enough $T$ to reach the increasing branch of the $d$ excess curve. This is the reason that the $d$ excess does not increase (yet) in the direction of the Antarctic interior. We thus expect higher values of $d$ excess for trajectories toward more remote regions in Antarctica.

Table 3. Characteristics of Seasonally Averaged Distillation Paths ${ }^{\mathrm{a}}$

\begin{tabular}{|c|c|c|c|c|c|c|c|c|c|}
\hline & \multicolumn{3}{|c|}{ DJF } & \multicolumn{3}{|c|}{ JJA } & \multicolumn{3}{|c|}{ DJF-JJA } \\
\hline & $\delta^{18} \mathrm{O}_{p}, \%$ & $\Delta T, \mathrm{~K}$ & $\delta^{18} \mathrm{O}_{\Delta T}, \%$ & $\delta^{18} \mathrm{O}_{p}, \%$ & $\Delta T, \mathrm{~K}$ & $\delta^{18} \mathrm{O}_{\Delta T}, \%$ & $\Delta \delta^{18} \mathrm{O}_{\mathrm{tot}}, \%$ & $\Delta \delta^{18} \mathrm{O}_{\Delta T}, \% 0$ & $\Delta \delta^{18} \mathrm{O} \delta_{v, \text { ini }}, \%$ \\
\hline AWS 4 & -13.2 & 7.1 & 5.6 & -19.9 & 11.2 & 8.3 & 6.7 & 2.7 & 4.0 \\
\hline AWS 5 & -17.0 & 11.2 & 7.5 & -22.7 & 15.2 & 12.3 & 5.7 & 4.8 & 0.9 \\
\hline AWS 6 & -20.5 & 20.9 & 12.2 & -28.8 & 21.4 & 15.2 & 8.3 & 3.0 & 5.3 \\
\hline AWS 9 & -26.0 & 20.7 & 13.7 & -37.3 & 32.2 & 23.3 & 11.3 & 9.6 & 1.7 \\
\hline
\end{tabular}

${ }^{a}$ The $\delta^{18} \mathrm{O}_{p}$ denotes final isotopic composition of the snowfall, $\Delta T$ is the difference in $T$ over which distillation has occurred, $\delta^{18} \mathrm{O} \Delta_{T}$ is the amount of distillation explained by $\Delta T$. The DJF-JJA columns give the total seasonal isotopic difference in the snowfall, the amount of this difference explained by $\Delta T$, and the (remaining) difference explained by the initial isotopic composition of the moisture, respectively. 


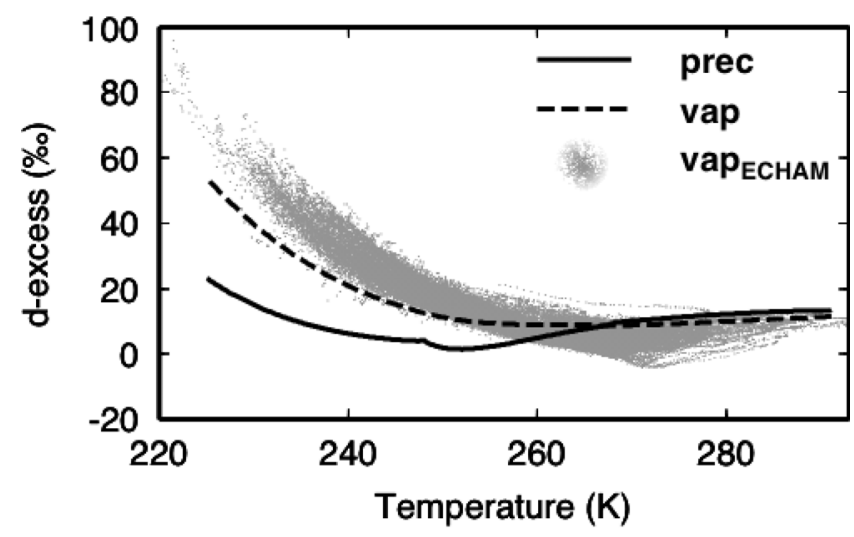

Figure 13. Modeled $d$ excess of vapor (dashed line) and precipitation (solid line) as a function of temperature along an idealized trajectory. The $d$ excess values of vapor from ECHAM are plotted in gray against temperature in ECHAM for all air parcel positions for AWS 9.

[54] An indication of higher $d$ excess values with low $T$ can be found in the variability in $d$ excess (shown as the grey bars in Figure 11). Much more deviations from the mean value on the positive side of the $d$ excess range occur compared to deviations on the negative side. This is most evident for AWS 9 and the explanation for this is that events leading to such high $d$ excess values are associated with lower $T$ than average. Since these cold accumulation events are typically associated with only a small amount of snowfall, the weighted mean $d$ excess is much lower than would be expected from the minimum and maximum value.

[55] We can also compare our modeled values of $d$ excess in the vapor phase with ECHAM4. In Figure 13, mean monthly $d$ excess values of the vapor in ECHAM4 are plotted in grey as a function of mean monthly temperatures in ECHAM4 for pathways toward AWS 9. For the sake of clarity, modeled $d$ excess is plotted against trajectory $T$ only for an idealized temperature history. This comparison shows that the two parameters generally behave in a comparable way. Only at very low $T$, the $d$ excess in ECHAM4 increases more strongly than our modeled $d$ excess. These results point out that the apparent large difference in $d$ excess in ECHAM4 and in our modeling results in Figure 11 is caused by $T$ differences between the ECHAM4 climatology (all conditions) on the one hand and the trajectories for snowfall events on the other hand, during which warm conditions prevail. The different behavior of $d$ excess at very low $T$ can be attributed to a slightly lower degree of supersaturation $\left(S_{i}\right)$ in ECHAM [Hoffmann et al., 1998] (parameterized as a function of $T$ as follows: $S_{i}=$ $1-0.003 T)$ compared to $S_{i}$ applied here $\left(S_{i}=1.02-\right.$ $0.0038 T)$. Schmidt et al. [2005] showed that higher values of $S_{i}$ (such as used here) yields a more realistic $d$ excess pattern over Antarctica compared to the parameterization generally used in GCMs.

\section{Simulated Snow Pit Records}

[56] To enable a comparison of modeled isotopic composition of precipitation with that measured in snow pits, the diffusion in the firn is taken into account (see Appendix A). By modeling both isotopic distillation during atmospheric transport and postdepositional diffusion occurring in the firn layer, we have obtained simulated isotope records that can be compared with the isotope records, as sampled in the Antarctic field season 2001-2002 (Table 2). A comparison of modeled and observed records can reveal the validity of our modeling approach.

[57] Both modeled (solid lines) and observed records (dashed lines) are shown in Figure 14. Furthermore, we summarized our results in Table 4 in terms of mean values and standard deviations (which can be interpreted as an indicator for the seasonal amplitude). Table 4 also shows a column with isotope values from ECHAM4. These values result from an experiment using monthly mean isotope values in precipitation from ECHAM4 (not shown in Figure 14), instead of our model experiment using backward trajectories.

\subsection{The $\delta^{18} \mathrm{O}$ Records}

[58] The results for the $\delta^{18} \mathrm{O}$ records differ from site to site. For the coastal site AWS 4 (Figure 14a) it was not possible to reveal the entire accumulation record, due to failure of the SHR, which prohibits a reconstruction of the upper $1.5 \mathrm{~m}$. The remaining part of the reconstructed record resembles the observations reasonably, although the winter values are not as depleted as the observations. This results in a less negative mean value compared to the observations (Table 4).

[59] Modeled and observed records are out of phase over a large part of the record of AWS 5 (between $\sim 0.5 \mathrm{~m}$ and $\sim 1.5 \mathrm{~m}$; Figure 14c). The most probable reason for this is that for AWS 4 and 5, the snow pit samples were extracted somewhat away from the AWSs (Table 2). This implies that the SHR might have recorded a different accumulation history than was sampled in the snow pit, since spatial accumulation variability can be substantial at very short distances due to sastrugi formation [Isaksson et al., 1996; Frezzotti et al., 2002; King et al., 2004]. Nevertheless, both mean value and seasonal amplitude of the record at AWS 5 are well reconstructed.

[60] The snow pit samples at AWS 6 and 9 were taken exactly under the SHR (Table 2), which should lead to a much better correspondence between modeled and observed isotope profiles. For AWS 6, this is indeed the case: the shape of the modeled $\delta^{18} \mathrm{O}$ record at AWS 6 (Figure 14e) agrees well with the measured record. However, over the entire period, modeled $\delta^{18} \mathrm{O}$ is shifted compared to the observed record, i.e., fractionation along the trajectories is underestimated by $5.3 \%$ on average (Table 4 ). This underestimation of the fractionation is larger in winter, since the modeled winter minima are less pronounced than the observed winter minima.

[61] Agreement is not so good for AWS 9. The mean modeled $\delta^{18} \mathrm{O}$ is not depleted enough (difference is $8.2 \%$ on average), and although the samples were taken directly under the SHR, the location of the seasonal maxima do not coincide with the observed record. However, the magnitude of the seasonal amplitude does agree with the observations. Possible reasons for the underestimation of the isotopic distillation will be addressed in section 6 .

[62] If we compare our model results to the records obtained using monthly mean values from the ECHAM4 

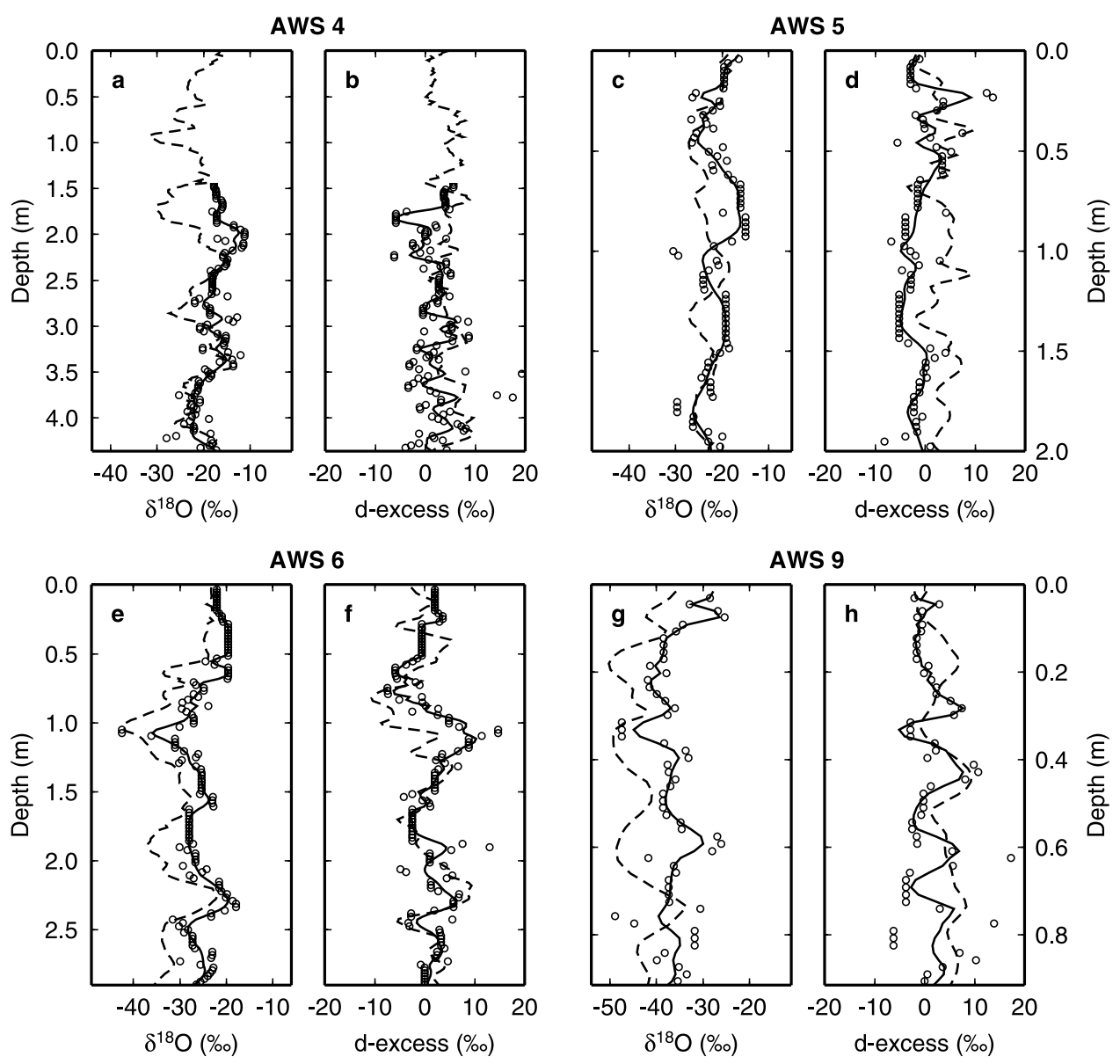

Figure 14. Modeled and observed isotope records at the four sites. Dashed lines represent the observations, open circles are the modeled undiffused values and the solid lines show the modeled isotope records after diffusion.

climatology (Table 4) it appears that our model results match the mean observed records better for AWS 4 and 5, while the ECHAM records are closer to the observed mean values for AWS 6 and 9. However, looking at the seasonal amplitude, we see that our approach is much more successful in reproducing the magnitude of the seasonal cycle compared to ECHAM4, which may be due to the use of monthly mean isotopic values from ECHAM4, instead of event-based values.

[63] A robust measure for the comparison between model results and observations is of course the correlation coefficient $r$. However, for a sound estimation of $r$, it is important that modeled and observed isotope values correspond to the same event. Because of uncertainties concerning the estimation of the depth of each event (see section 2), and taken into account that the snow pits at AWS 4 and 5 are not sampled directly under the SHR, a comparison of the records only resulted in an acceptable correlation between modeled and observed isotope records for AWS $6(r=$ 0.86). At AWS 9, a combination of the low accumulation (only $74 \mathrm{~kg} \mathrm{~m}^{-2} \mathrm{yr}^{-1}$ ) and the (unknown) influence of redistribution of snow by snow drift is probably the reason for the low resemblance between the modeled and observed record. In general, the error introduced by the use of monthly mean ECHAM4 isotope fields as initial isotopic values may be the reason of the discrepancy with the observed isotope variability.

\subsection{Deuterium Excess}

[64] The precision of the mass spectrometer used to determine the isotopic composition of the samples is in the order of $0.1 \%$ in $\delta^{18} \mathrm{O}$ and $2.0 \%$ in $\delta \mathrm{D}$. Because of the

Table 4. Statistical Properties of Modeled and Observed Isotope Records

\begin{tabular}{|c|c|c|c|c|c|c|}
\hline & \multicolumn{3}{|c|}{ Mean } & \multicolumn{3}{|c|}{$\sigma$} \\
\hline & $\begin{array}{c}\text { Observed, } \\
\% \text { \% }\end{array}$ & $\begin{array}{c}\text { ECHAM, } \\
\% 0\end{array}$ & $\begin{array}{c}\text { Modeled, } \\
\% \text { \% }\end{array}$ & $\begin{array}{c}\text { Observed, } \\
\% 0 \\
\end{array}$ & $\begin{array}{c}\text { ECHAM, } \\
\% \\
\end{array}$ & $\begin{array}{c}\text { Modeled, } \\
\% \text { \% }\end{array}$ \\
\hline \multicolumn{7}{|c|}{$\delta^{18} \mathrm{O}$} \\
\hline AWS 4 & -21.4 & -16.4 & -17.7 & 4.2 & 0.8 & 2.7 \\
\hline AWS 5 & -23.3 & -19.3 & -21.3 & 2.5 & 0.9 & 2.9 \\
\hline AWS 6 & -30.4 & -27.2 & -25.1 & 5.1 & 2.3 & 3.7 \\
\hline AWS 9 & -43.6 & -38.9 & -35.4 & 3.4 & 2.5 & 3.6 \\
\hline \multicolumn{7}{|c|}{$d$ Excess } \\
\hline AWS 4 & 4.9 & 2.3 & 1.5 & 2.6 & 1.5 & 2.5 \\
\hline AWS 5 & 3.3 & 2.2 & -1.2 & 3.0 & 0.9 & 2.7 \\
\hline AWS 6 & 0.0 & 3.8 & 1.3 & 4.6 & 2.3 & 3.4 \\
\hline AWS 9 & 4.0 & 11.5 & 2.8 & 3.4 & 1.9 & 3.4 \\
\hline
\end{tabular}


relatively high uncertainty in the resulting $d$ excess parameter $(2.2 \%$ ) , the raw $d$ excess records were somewhat noisy. We applied a three-point running average on $d$ excess data to smooth the records (dashed lines in Figure 14).

[65] In general, the modeled $d$ excess variations are rather close to the observed records. Only at AWS 5 a bias is found from the observed record, but this can be explained by the difference in sampled snow and monitored accumulation by the SHR, as mentioned above. Even at AWS 9, where the modeled $\delta^{18} \mathrm{O}$ record was not correctly reproduced, the $d$ excess values are close to the observed record. This means that $\delta \mathrm{D}$ deviates in a comparable way from the observations as $\delta^{18} \mathrm{O}$. While for the mean $\delta^{18} \mathrm{O}$ values our approach agreed best with AWS 4 and 5, the mean $d$ excess is better reproduced for AWS 6 and 9. As for the $\delta^{18} \mathrm{O}$ records, the seasonal amplitude in $d$ excess is successfully reproduced (Table 4).

[66] A comparison with the $d$ excess values resulting from the ECHAM4 climatology reveals a large deviation from the observed $d$ excess value at AWS 9. Clearly, ECHAM4 produces too high $d$ excess values at low temperatures, which is not in line with our observations. Generally, $d$ excess records are deconvolved into a local forcing (site temperature) and a forcing due to changes in the moisture source area (sea surface temperature, RH, and wind speed) [e.g., Stenni et al., 2001; Masson-Delmotte et al., 2004]. In section 6 we will address to what extent $d$ excess is determined by the source area, compared to changes during transport.

\section{Discussion}

[67] There is a tendency in our results obtained using the MCIM to underestimate isotopic distillation at lower site temperatures. This is most clearly shown at AWS 9 (Figure 14, where the difference between the mean modeled and observed $\delta^{18} \mathrm{O}$ value at this site is $8.2 \%$ (Table 4). To a lesser extent, the observed $\delta^{18} \mathrm{O}$ record at AWS 6 also shows more depleted values than the modeled isotope record, especially in winter. There are several possible explanations for this underestimation.

[68] First, we imposed a $\mathrm{RH}_{\text {threshold value of } 80 \% \text { as an }}$ indicator for condensation to occur. From Figure 5 it appears that especially the trajectories to AWS 6 and 9 show lower RH values along a major part of the transport.

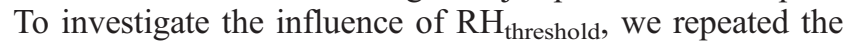
MCIM runs for AWS 9 with $\mathrm{RH}_{\text {threshold }}=60 \%$. The resulting mean modeled $\delta^{18} \mathrm{O}$ value decreased only $2.1 \%$ to $-37.5 \%$. This is only a minor improvement, especially since it is not expected that condensation will occur in reality when $\mathrm{RH}$ is only $60 \%$. From Figure $5 \mathrm{~d}$ it appears that RH generally is higher than $80 \%$ during the last day of transport, when the major drop in $T$ occurs. This explains the relatively small influence of the threshold value of $\mathrm{RH}$ on the total depletion of the moisture. These results point toward another reason for the large difference between model results and observations at AWS 9.

[69] Second, the MCIM assumes that part of the water that forms during condensation is kept in the cloud. This slightly reduces the isotopic distillation compared to Rayleigh fractionation (i.e., all the condensed water is immediately removed from the cloud). Using pure Rayleigh fractionation, the final $\delta^{18} \mathrm{O}_{p}$ value for AWS 9 decreases by only $1.9 \%$. This indicates that the choice of the distillation-type cannot explain the difference in observed and modeled $\delta^{18} \mathrm{O}$ values either.

[70] Third, the quality of the ERA-40 data set as an input for the trajectory model can be a reason for the underestimation of the fractionation. ERA-40 is badly constrained by observations in a data-sparse region like the high Antarctic plateau. An underestimation of the $T$ difference between $T_{\mathrm{RH}=80 \%}$ and $T_{c \text {,final }}$ in ERA-40 could well explain the lack of sufficient fractionation toward high elevation sites like AWS 9. However, it is not possible to test this hypothesis, since no independent information of $T_{\mathrm{RH}=80 \%}$ is available. We can only compare the final condensation temperature in the trajectories $\left(T_{c, \text { final }}\right)$ with results from the regional climate model RACMO2/ANT [Reijmer et al., 2005]. This model is forced by ERA-40 at its boundaries, but it simulates the Antarctic climate at a much higher resolution $(\sim 55 \mathrm{~km})$. We defined condensation temperature in the regional climate model $\left(T_{c, \mathrm{RACMO}}\right)$ as the temperature with maximum $C W C$ above the location of the AWSs [Helsen et al., 2005]. Since RACMO2/ANT has proven to yield more realistic results for the Antarctic region than ERA-40 [Reijmer et al., 2005], we expected to find differences between $T_{c \text {,final }}$ and $T_{c \text {, RACMO, but no substantial differences }}$ were revealed. If $T_{c, \text { RACMO }}$ is a good representation of the real $T_{c}$ over AWS 9, these findings reject our suggestion that the quality of ERA-40 is the reason for the underestimation of the distillation at low temperatures.

[71] There are some other possible explanations for the underestimation of the depletion, which are more difficult to verify. For instance, isotopic equilibration of snow and firn with vapor from the boundary layer [Waddington et al., 2002] or from deeper firn layers [Motoyama et al., 2005] has not been accounted for in the diffusion model. Furthermore, the contribution of clear-sky precipitation to the total accumulation is unknown, but it is believed to be an important contribution to the total accumulation in the Antarctic interior [Bromwich, 1988]. This type of precipitation has not been accounted for in our approach, since trajectories are only calculated when condensed moisture is detected above the surface. Clear-sky precipitation is likely more depleted than cyclonic precipitation because it is formed from residual vapor from previous storms, that condensates at lower temperatures due to radiative cooling of saturated air. On the other hand, as snowfall events at AWS 9 are coupled to more intense cyclones compared to more coastal sites, the isotopic composition of the moisture within these cyclones may deviate more from the mean state as within low-intense cyclones. Together with the fewer number of large events in the Antarctic interior, this may prohibit the use of climatologically monthly mean ECHAM4 isotope fields as a starting value for the trajectory study for this location. Finally, the influence of turbulent mixing of moisture in the air masses with more depleted ambient moisture has not been taken into account, since the calculated trajectories just follow the air parcels and not necessarily the moisture within them. This can be an important additional source of more depleted moisture.

[72] There is a similarity between modeled and observed $d$ excess values (Table 4 and Figure 14), and this offers the possibility to study the forcing behind the $d$ excess signal. 
We separated the modeled $d$ excess results for AWS 6, into two groups of high and low $d$ excess values, using the local mean value of $1.3 \%$ as separation. Weighted mean trajectories were calculated for both groups. It appears that all relevant parameters (e.g., $T$, source area) are practically equal for both groups. There was only a difference in height: the trajectories resulting in high $d$ excess values were advected toward their arrival location at a higher altitude compared to the low $d$ excess trajectories. This is illustrated in Figure 15b, in which the dotted line indicates the mean pressure of the trajectories with a high $d$ excess value, and the dashed line represents the mean pressure of the trajectories resulting in low $d$ excess values. The implication of this difference in height can be seen in Figure 15a, which shows a contour plot of $d$ excess $_{v, \text { ECHAM }}$ values, along a section following the meridian over AWS 6 . A strong vertical gradient can be recognized. The effect of this vertical gradient on our modeling results is obvious: trajectories starting near the ocean surface start with vapor with a much lower initial $d$ excess value (from the ECHAM4 fields) than trajectories that originate from a height of several $\mathrm{km}$. For the two groups considered, the difference in $d$ excess due to the initial value is $3.2 \%$, which is $60 \%$ of the final difference in $d$ excess $(5.3 \%)$.

[73] This remaining part of the final difference in $d$ excess between the two groups of trajectories $(40 \%)$ can be attributed to differences in kinetic fractionation along the transport path, especially during the last day of transport. The solid line in Figure $15 \mathrm{c}$ indicates $\Delta d$ excess, and it illustrates that for the two groups considered, the behavior of $d$ excess is rather similar along the major part of the transport. The final drop of $d$ excess during the last day of transport (previously seen in Figure 11) is slightly stronger for the trajectories with low $d$ excess values (dashed line), which explains the remaining $2.1 \%$ difference in the mean value of $d$ excess.

[74] This analysis shows that the ECHAM4 fields influence the $d$ excess modeling results to a large extent. Because of a general lack of measurements of atmospheric $d$ excess values, it remains unclear whether GCMs like ECHAM4 produce realistic patterns of atmospheric $d$ excess. A comparison of different GCM-generated $d$ excess fields (such as the Stable Water Isotope intercomparison Group (SWING) (M. Werner, personal communication, 2005)) seems therefore valuable. Nevertheless, the similarity between modeled and observed $d$ excess records from this study is an indication that the vertical gradient in the $d$ excess values of the vapor in ECHAM4 is in line with reality.

[75] The $d$ excess parameter is often used to extract (paleo-) climatic information of moisture source areas, i.e., RH and sea surface temperature (SST) [e.g., Johnsen et al., 1989; Vimeux et al., 1999; Masson-Delmotte et al., 2003]. It is clear that the relative imprint of the initial $d$ excess value compared to the final $d$ excess value of the precipitation differs depending on the distillation history. Unfortunately, our approach does not provide information about evaporation conditions of the moisture. Consequently, we cannot directly determine to which extent these conditions are preserved along the trajectories. However, our results suggest a prominent influence of the vertical gradient in $d$ excess over the moisture source region. Noone and
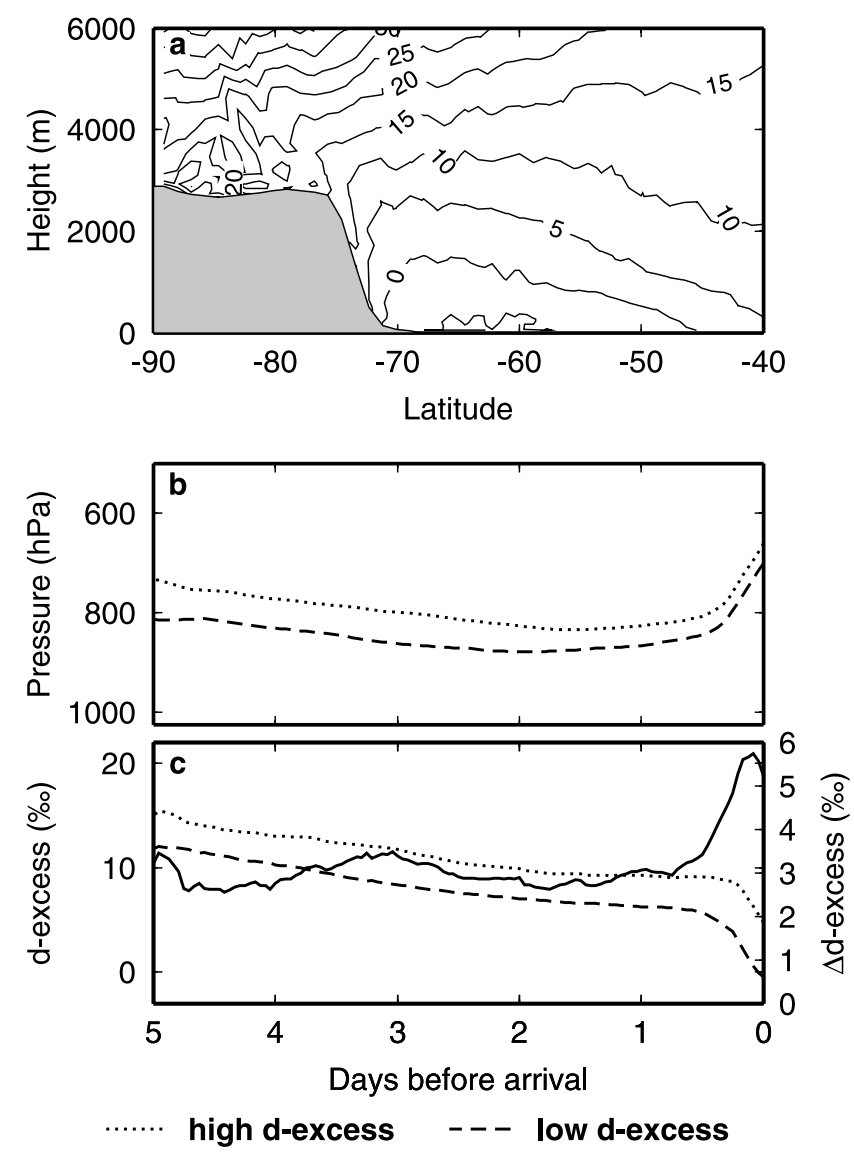

Figure 15. (a) Mean $d$ excess values of vapor for January in ECHAM4, (b) mean pressure levels, and (c) modeled $d$ excess values of precipitation along trajectories calculated for AWS 6. Dotted lines represent trajectories producing high $d$ excess values, dashed lines represents trajectories producing low $d$ excess values. Solid line indicates $\Delta d$ excess.

Simmonds [2004] pointed out that variations in sea ice distribution can have a considerable effect on atmospheric transport and ultimately on the $d$ excess signal. In our analysis however, no direct dependence of $d$ excess on sea ice fraction was identified along the trajectories. However, it is likely that the vertical isotopic gradients in $d$ excess are influenced by the presence of sea ice, through a reduced equilibration of atmospheric vapor with evaporating water. Furthermore, a reduced sea ice cover will reduce the amount of diabatic cooling over the pack ice, which will result in a higher level of turbulent ascent of the moisture [Noone and Simmonds, 2004]. Hence a strong gradient of $d$ excess (increasing $d$ excess values with height) will especially develop over sea ice, while open water will suppress the development of such a gradient. This would mean that the higher $d$ excess values on a higher atmospheric level reflect a more distant (tropical?) moisture source, while the low near-surface $d$ excess values can be attributed to evaporation at higher latitudes, which is in line with the current interpretation of $d$ excess in polar ice cores [e.g., Vimeux et al., 1999]. However, it is questionable to what extent RH or SST can leave an imprint in the vertical gradient in $d$ excess over the oceanic source area. Therefore 


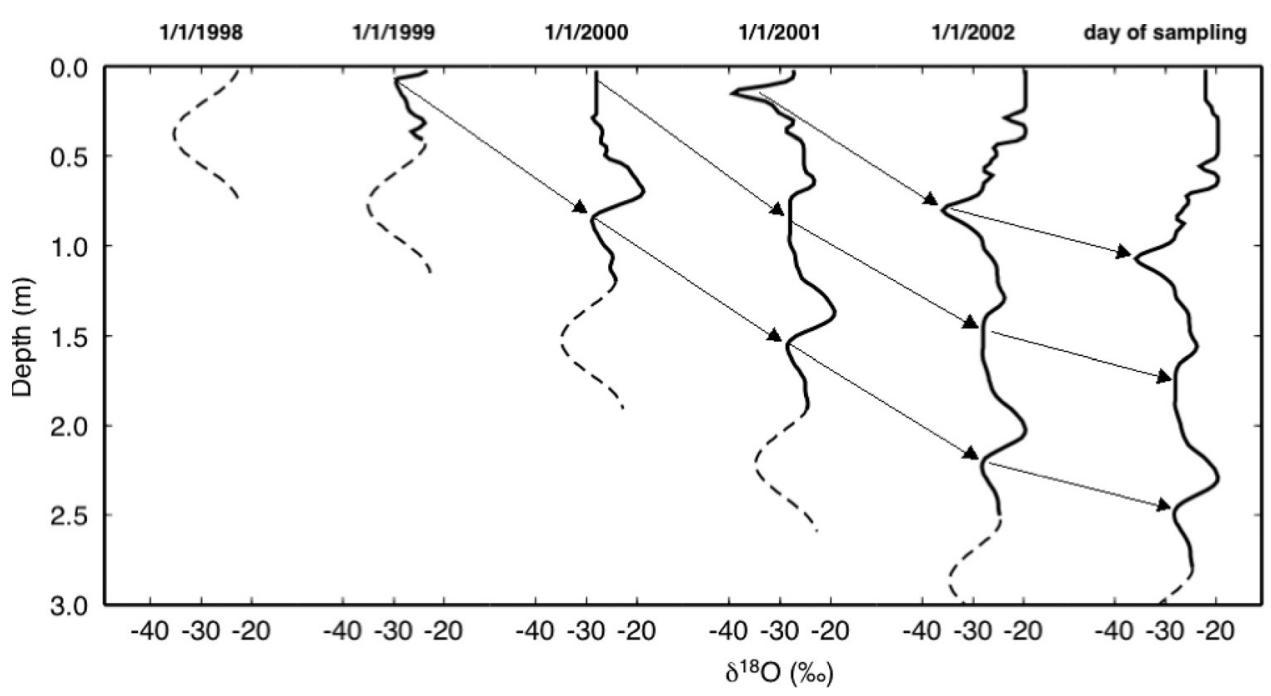

Figure A1. Evolution of the $\delta^{18} \mathrm{O}$ record at AWS 6. Arrows indicate the vertical shifts of winter minima in subsequent years.

more insights are needed in the dynamics behind the vertical distribution of the initial $d$ excess values of the vapor over the ocean.

\section{Conclusions}

[76] Simple isotope distillation models have since long been proved useful in terms of explaining observed spatial gradients [e.g., Jouzel and Merlivat, 1984] and seasonal cycles [e.g., Ciais et al., 1995]. In this paper we went further in applying such a model on individual events.

[77] We used a combination of back trajectory calculations and isotopic modeling to simulate the isotopic composition of four snow pits in Dronning Maud Land, Antarctica. The trajectories indicate a moisture source area in the southern Atlantic Ocean. The major part of the isotopic fractionation occurs during the last day of transport, when the air masses experience cooling due to the orographic lift over the Antarctic continent. The strength of this final $T$ drop is of primary importance to both the $\delta^{18} \mathrm{O}$ and the $d$ excess value of the final precipitation. However, the seasonal amplitude can only partly be explained by the magnitude of this $T$ drop. Seasonal variations of the isotopic composition of the initial moisture are also important for the final isotopic composition of the snow.

[78] Although we are aware that the use of climatological isotope values (as modeled by the ECHAM4 GCM) as the initial state is a possible major source of error, the resemblance between modeled and observed isotope variations is fairly good, from which we conclude that this approach is able to realistically simulate the isotopic fractionation. However, for the high Antarctic plateau the isotopic distillation is underestimated. The reasons for this underestimation remain unclear. A forthcoming study will further address the spatial and temporal patterns of both $\delta^{18} \mathrm{O}$ and $d$ excess in Antarctic precipitation.

\section{Appendix A}

[79] Isotopic diffusion in firn is taken into account by using the firn diffusion model as described by Johnsen et al.
[2000]. This model is able to realistically describe the effective smoothing of isotope records through time. For a full explanation of the theory we refer to their work, here we briefly explain how this model was included in our analyses.

[80] Considering a coordinate system with a vertical $z$ axis and an origin at the surface, the isotopic composition $\delta_{i}$ of nondeforming firn changes over time $t$ according to

$$
\frac{\partial \delta_{i}}{\partial t}=\frac{m e_{s} \omega_{a i}}{R T \alpha_{i} \tau}\left(\frac{1}{\rho_{f}}-\frac{1}{\rho_{\text {ice }}}\right) \frac{\partial^{2} \delta_{i}}{\partial z^{2}}
$$

where $m$ is the molar weight of water, $e_{s}$ is the saturation vapor pressure over ice, $\omega_{a i}$ is the diffusivity of the isotopic species $i$ in open air, $R$ is the universal gas constant, $T$ temperature, $\alpha_{i}$ is the ice-vapor equilibrium fractionation factor for the isotopic species $i, \tau$ is the tortuosity factor, $\rho_{f}$ is the density of the firn, and $\rho_{\text {ice }}$ is the density of ice. Using equation (A1), the diffusion rate is especially sensitive for $T$ and $\rho_{f}$. We obtained subsurface values of $T$ from energy balance calculations by Van den Broeke et al. [2005]. During sampling, $\rho_{f}$ has been measured. We used a fitted power law function for $\rho_{f}$ at each site, and assumed that this relation is constant over time. For all other parameters in equation (A1) we used expressions as suggested by Johnsen et al. [2000].

[81] To minimize the effects of boundary conditions, we added one artificial sinusoidal seasonal cycle and started the diffusion model at 1 January 1998. Each day when accumulation occurred according to the SHR record, this snow is added on top of the diffusion domain, and the origin of the $z$ axis is shifted to the surface. We account for the densification of the snow by calculating new density values for the modeled domain each time a shift of the $z$ axis occurs (i.e., after each accumulation event).

[82] In Figure A1, modeled growth of the $\delta^{18} \mathrm{O}$ record at AWS 6 is shown. The $\delta^{18} \mathrm{O}$ record is plotted for each modeled year, starting with the prescribed sinusoidal seasonal cycle at 1 January 1998, followed by four subsequent years of accumulation and diffusion, and ending on the day 
when the snow pit samples were taken, early 2002. The isotope record is initially irregular and often includes several subseasonal variations. However, firn diffusion quickly smoothes these features, and after some years the only remaining signal is the annual cycle. Striking are also the differences in decrease of seasonal amplitudes, which are largely dependent on the second derivative term in equation (A1): the diffusion process has a much larger effect on the strongly negative $\delta^{18} \mathrm{O}$ winter 2000 minimum, compared to the broader minimum of winter 1999 (Figure 16).

[83] Acknowledgments. This work is a contribution to the European Project for Ice Coring in Antarctica (EPICA), a joint ESF (European Science Foundation)/EC scientific programme, funded by the European Commission and by national contributions from Belgium, Denmark, France, Germany, Italy, Netherlands, Norway, Sweden, Switzerland, and the United Kingdom. This is EPICA publication 151. Financial support was obtained from the Netherlands Organisation for Scientific Research (NWO) by a grant of the Netherlands Antarctic Programme. We thank three anonymous reviewers, whose comments have considerably improved this manuscript.

\section{References}

Aldaz, L., and S. Deutsch (1967), On a relationship between air temperature and oxygen isotope ratio of snow and firn in the South Pole region, Earth Planet. Sci. Lett., 3, 267-274.

Boyle, E. A. (1997), Cool tropical temperatures shift the global $\delta^{18} \mathrm{O}-T$ relationship: An explanation for the ice core $\delta^{18} \mathrm{O}$-borehole thermometry conflict?, Geophys. Res. Lett., 24(3), 273-276.

Bromwich, D. H. (1988), Snowfall in high southern latitudes, Rev. Geophys., 26(1), 149-168.

Ciais, P., and J. Jouzel (1994), Deuterium and oxygen 18 in precipitation: Isotopic model, including mixed cloud preocesses, J. Geophys. Res., 99(D8), 16,793-16,803.

Ciais, P., J. W. C. White, J. Jouzel, and J. R. Petit (1995), The origin of present-day Antarctic precipitation from surface snow deuterium excess data, J. Geophys. Res., 100(D9), 18,917-18,927.

Craig, H., and A. Gordon (1965), Deuterium and oxygen 18 variations in the ocean and the marine atmosphere, in Stable Isotopes in Oceanic Studies and Paleotemperatures, pp. 9-130, Lab. di Geol. Nucl., Pisa, Italy.

Cuffey, K. M., and F. Vimeux (2001), Covariation of carbon dioxide and temperature from the Vostok ice core after deuterium-excess correction, Nature, 412, 523-527.

Cuffey, K. M., G. D. Clow, R. B. Alley, M. Stuiver, E. D. Waddington, and R. W. Saltus (1995), Large Arctic temperature change at the WisconsinHolocene glacial transition, Science, 270, 455-458.

Dahe, Q., J. R. Petit, J. Jouzel, and M. Stievenard (1994), Distribution of stable isotopes in surface snow along the route of the 1990 International Trans-Antarctic Expedition, J. Glaciol., 40(134), 107-118.

Dansgaard, W. (1964), Stable isotopes in precipitation, Tellus, 16, 436468.

Delaygue, G., V. Masson, J. Jouzel, R. D. Koster, and R. J. Healy (2000), The origin of Antarctic precipitation: A modelling approach, Tellus, Ser. $B, 52,19-36$.

Delmotte, M., V. Masson, J. Jouzel, and V. Morgan (2000), A seasonal deuterium excess signal at Law Dome, coastal eastern Antarctica: A Southern Ocean signature, J. Geophys. Res, 105(D6), 7187-7197.

EPICA Community Members (2004), Eight glacial cycles from an Antarctic ice core, Nature, 429, 623-628.

Fisher, D. A. (1991), Remarks on the deuterium excess in precipitation in cold regions, Tellus, Ser. B, 43, 401-407.

Frezzotti, M., S. Gandolfi, and S. Urbini (2002), Snow megadunes in Antarctica: Sedimentary structure and genesis, J. Geophys. Res., 107(D18), 4344, doi:10.1029/2001JD000673.

GRIP Members (1993), Climate instability during the last interglacial period recorded in the GRIP ice core, Nature, 364, 203-207.

Helsen, M. M., R. S. W. Van de Wal, M. R. Van den Broeke, E. R. T. Kerstel, V. Masson-Delmotte, H. A. J. Meijer, C. H. Reijmer, and M. P. Scheele (2004), Modelling the isotopic composition of snow using backward trajectories: A particular accumulation event in Dronning Maud Land, Antarctica, Ann. Glaciol., 39, 293-299.

Helsen, M. M., R. S. W. Van de Wal, M. R. Van den Broeke, D. Van As, H. A. J. Meijer, and C. H. Reijmer (2005), Oxygen isotope variability in snow from western Dronning Maud Land, Antarctica and its relation to temperature, Tellus, Ser. B, 57(5), 423-435.

Hoffmann, G., M. Werner, and M. Heimann (1998), Water isotope module of the ECHAM atmospheric general circulation model: A study on time scales from days to several years, J. Geophys. Res., 103(D14), 16,87116,896 .

International Atomic Energy Agency (1992), Statistical treatment of data on environmental isotopes in precipitation, IAEA Tech. Rep. Ser. 331, Vienna. Isaksson, E., W. Karlén, N. Gundestrup, P. Mayewski, S. Whitlow, and M. Twickler (1996), A century of accumulation and temperature changes in Dronning Maud Land, Antarctica, J. Geophys. Res., 101(D3), 70857094.

Jakob, C. (1999), Cloud cover in the ECMWF Reanalysis, J. Clim., 12(4), 947-959.

Johnsen, S. J., W. Dansgaard, and J. W. C. White (1989), The origin of Arctic precipitation under present and glacial conditions, Tellus, Ser. B, 41, $452-468$.

Johnsen, S. J., D. Dahl-Jensen, W. Dansgaard, and N. Gundestrup (1995), Greenland palaeotemperatures derived from GRIP bore hole temperature and ice core isotope profiles, Tellus, Ser. B, 47, 624-629.

Johnsen, S. J., H. B. Clausen, K. M. Cuffey, G. Hoffmann, J. Schwander, and T. Creyts (2000), Diffusion of stable isotopes in polar firn and ice: The isotope effect in firn diffusion, in Physics of Ice Core Records, edited by T. Hondoh, pp. 121-140, Hokkaido Univ. Press, Sapporo, Japan.

Joussaume, J., R. Sadourny, and J. Jouzel (1984), A general circulation model of water isotope cycles in the atmosphere, Nature, 311, 24-29.

Jouzel, J., and R. D. Koster (1996), A reconsideration of the initial conditions used for stable water isotope models, J. Geophys. Res., 101(D17), 22,933-22,938.

Jouzel, J., and L. Merlivat (1984), Deuterium and oxygen 18 in precipitation: Modeling of the isotopic efects during snow formation, J. Geophys. Res., 89(D7), 11,749-11,757.

Jouzel, J., et al. (1997), Validity of the temperature reconstruction from water isotopes in ice cores, J. Geophys. Res., 102(C12), 26,471-26,487.

Jouzel, J., F. Vimeux, N. Caillon, G. Delaygue, G. Hoffmann, V. MassonDelmotte, and F. Parrenin (2003), Magnitude of isotope/temperature scaling for interpretation of central antarctic ice cores, J. Geophys. Res., 108(D12), 4361, doi:10.1029/2002JD002677.

Kavanaugh, J. L., and K. M. Cuffey (2003), Space and time variation of $\delta^{18} \mathrm{O}$ and $\delta \mathrm{D}$ in Antarctic precipitation revised, Global Biogeochem. Cycles, 17(1), 1017, doi:10.1029/2002GB001910.

King, J. C., P. S. Andersen, D. G. Vaughan, G. W. Mann, S. D. Mobbs, and S. B. Vosper (2004), Wind-borne redistribution of snow across an Antarctic ice rise, J. Geophys. Res., 109, D11104, doi:10.1029/ 2003JD004361.

Kottmeier, C., and B. Fay (1998), Trajectories in the antarctic lower troposphere, J. Geophys. Res., 103(D9), 10,947-10,959.

Landais, A., J. M. Barnola, V. Masson-Delmotte, J. Jouzel, J. Chappellaz, N. Caillon, C. Huber, and S. J. Johnsen (2004), A continuous record of temperature evolution over a sequence of Dansgaard-Oeschger events during Marine Isotopic Stage 4 (76 to $62 \mathrm{kyr}$ BP), Geophys. Res. Lett., 31, L22211, doi:10.1029/2004GL021193.

Masson-Delmotte, V., M. Delmotte, V. Morgan, D. Etheridge, T. V. Ommen, S. Tartarin, and G. Hoffmann (2003), Recent southern Indian Ocean climate variability inferred from a Law Dome ice core: New insights for the interpretation of coastal Antarctic isotopic records, Clim. Dyn., 21(2), 153-166.

Masson-Delmotte, V., B. Stenni, and J. Jouzel (2004), Common millennialscale variability of Antarctic and Southern Ocean temperatures during the past 5000 years reconstructed from the EPICA Dome C ice core, Holocene, 14(2), 145-151.

Merlivat, L., and J. Jouzel (1979), Global climatic interpretation of the deuterium-oxygen 18 relationship for precipitation, J. Geophys. Res., 84(C8), 5029-5033.

Motoyama, H., N. Hirasawa, K. Satow, and O. Watanabe (2005), Seasonal variations in oxygen isotope ratios of daily collected precipitation and wind drift samples and in the final snow cover at Dome Fuji Station, Antarctica, J. Geophys. Res., 110, D11106, doi:10.1029/2004JD004953.

Noone, D., and I. Simmonds (2002a), Annular variations in moisture transport mechanisms and the abundance of $\delta^{18} \mathrm{O}$ in Antarctic snow, J. Geophys. Res., 107(D24), 4742, doi:10.1029/2002JD002262.

Noone, D., and I. Simmonds (2002b), Associations between $\delta^{18} \mathrm{O}$ of water and climate parameters in a simulation of atmospheric circulation for 1979-95, J. Clim., 15(22), 3150-3169.

Noone, D., and I. Simmonds (2004), Sea ice control of water isotope transport to Antarctica and implications for ice core interpretation, J. Geophys. Res., 109, D07105, doi:10.1029/2003JD004228.

Noone, D., J. Turner, and R. Mulvaney (1999), Atmospheric signals and characteristics of accumulation on Dronning Maud Land, Antarctica, J. Geophys. Res., 104(D16), 19,191-19,211. 
North Greenland Ice Core Project Members (2004), High-resolution record of Northern Hemisphere climate extending into the last interglacial period, Nature, 431, 147-151.

Peel, D. A., R. Mulvaney, and B. R. Davison (1988), Stable-isotope/airtemperature relationships in ice cores from Dolleman Island and the Palmer Land plateau, Antarctic Peninsula, Ann. Glaciol., 10, 130-136.

Petit, J. R., J. W. C. White, N. W. Young, J. Jouzel, and Y. Korotkevich (1991), Deuterium excess in recent Antarctic snow, J. Geophys. Res., 96(D3), 5113-5122.

Petit, J. R., et al. (1999), Climate and atmospheric history of the past 420,000 years from the Vostok ice core, Antarctica, Nature, 399, 429436.

Reijmer, C. H., and M. R. Van den Broeke (2003), Temporal and spatial variability of the surface mass balance in Dronning Maud Land, Antarctica, as derived from automatic weather stations, J. Glaciol., 49(167), $512-520$.

Reijmer, C. H., M. R. Van den Broeke, and M. P. Scheele (2002), Air parcel trajectories and snowfall related to five deep drilling locations in Antarctica based on the ERA-15 dataset, J. Clim., 15, 1957-1968.

Reijmer, C. H., E. Van Meijgaard, and M. R. Van den Broeke (2005), Evaluation of temperature and wind over Antarctica in a Regional Atmospheric Climate Model using one year of automatic weather station data and upper air observations, J. Geophys. Res., 110, D04103, doi:10.1029/ 2004JD005234.

Robin, G. (1983), The climatic record from ice cores, in The Climatic Record in Polar Ice Sheets, edited by G. Robin, pp. 180-195, Cambridge Univ. Press, New York.

Robin, G., and S. J. Johnsen (1983), Atmospheric processes, in The Climatic Record in Polar Ice Sheets, edited by G. Robin, pp. 47-52, Cambridge Univ. Press, New York.

Roeckner, E., K. Arpe, L. Bengtsson, M. Christoph, M. Claussen, L. Dmenil, M. Esch, M. Giorgetta, U. Schlese, and U. Schulzweida (1996), The atmospheric general circulation model ECHAM-4: Model description and simulation of present-day climate, MPI Rep. 218, MaxPlanck-Inst. for Meteorol., Hamburg, Germany.

Scheele, M. P., P. C. Siegmund, and P. F. J. Van Velthoven (1996), Sensitivity of trajectories to data resolution and its dependence on the starting point: In or outside a tropopause fold, Meteorol. Appl., 3, 267-273.

Schmidt, G. A., G. Hoffmann, D. T. Shindell, and Y. Hu (2005), Modeling atmospheric stable water isotopes and the potential for constraining cloud processes and stratosphere-troposphere water exchange, J. Geophys. Res., 110, D21314, doi:10.1029/2005JD005790.

Stenni, B., V. M.-D. S. Johnsen, J. Jouzel, A. Longinelli, E. Monnin, R. Röthlisberger, and E. Selmo (2001), An oceanic cold reversal during the last deglaciation, Science, 293, 2074-2077.

Stohl, A., G. Wotawa, P. Seibert, and H. Kromp-Kolb (1995), Interpolation errors in wind fields as a function of spatial and temporal resolution and their impact of different types of kinematic trajectories, J. Appl. Meteorol., 34(10), 2149-2165.

Tiedtke, M. (1993), Representation of clouds in large-scale models, Mon. Weather Rev., 121(11), 3040-3061.

Van den Broeke, M., C. Reijmer, and R. Van de Wal (2004), Surface radiation balance in Antarctica as measured with automatic weather stations, J. Geophys. Res., 109, D09103, doi:10.1029/2003JD004394.

Van den Broeke, M., C. Reijmer, D. Van As, R. Van de Wal, and J. Oerlemans (2005), Seasonal cycles of Antarctic surface energy balance from automatic weather stations, Ann. Glaciol., 41, 131-139.

Van Lipzig, N. P. M., E. Van Meijgaard, and J. Oerlemans (2002), The effect of temporal variations in the surface mass balance and temperatureinversion strength on the interpretation of ice-core signals, J. Glaciol., 48(163), 611-621.

Vimeux, F., V. Masson, J. Jouzel, and M. Stievenard (1999), Glacial-interglacial changes in ocean surface conditions in the Southern Hemisphere, Nature, 398, 410-413.

Vuille, M., R. S. Bradley, M. Werner, R. Healy, and F. Keimig (2003), Modelling $\delta^{18} \mathrm{O}$ in precipitation over the tropical Americas: 1. Interannual variability and climatic controls, J. Geophys. Res., 108(D6), 4174, doi:10.1029/2001JD002038.

Waddington, E. D., E. J. Steig, and T. A. Neumann (2002), Using characteristic times to assess whether stable isotopes in polar snow can be reversibly deposited, Ann. Glaciol., 35, 118-124.

Werner, M., and M. Heimann (2002), Modeling interannual variability of water isotopes in Greenland and Antarctica, J. Geophys. Res., 107(D1), 4001, doi:10.1029/2001JD900253.

Werner, M., U. Mikolajewicz, M. Heimann, and G. Hoffmann (2000), Borehole versus isotope temperatures on Greenland: Seasonality does matter, Geophys. Res.Lett., 27(5), 723-726.

Werner, M., M. Heimann, and G. Hoffmann (2001), Isotopic composition and origin of polar precipitation in present an glacial climate simulations, Tellus, Ser. B, 53, 53-71.

M. M. Helsen, M. R. van den Broeke, and R. S. W. van de Wal, Institute for Marine and Atmospheric Research, Utrecht University, P.O. Box 80.005, NL-3508 TA Utrecht, Netherlands. (m.m.helsen@phys.uu.nl)

V. Masson-Delmotte, Laboratoire des Sciences du Climat et de l'Environnement (LSCE), UMR CEA/CNRS 1572, Bat 709, L'Orme des Merisiers CEA, Saclay, F-91191 Gif sur Yvette Cedex, France.

H. A. J. Meijer, Centre for Isotope Research (CIO), Nijenborgh 4, NL-9747, AG Groningen, Netherlands.

M. P. Scheele, Royal Netherlands Meteorological Institute, P.O. Box 201, NL-3730 AE De Bilt, Netherlands.

M. Werner, Max-Planck-Institute for Biogeochemistry, P.O. Box 1001 64, D-07701 Jena, Germany. 